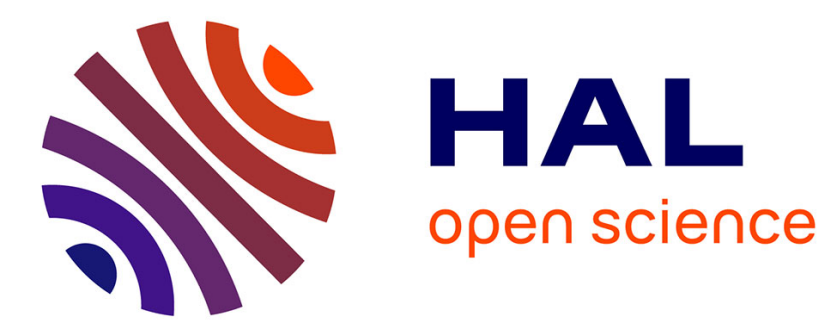

\title{
Aqueous Synthesis for Highly Emissive 3-Mercaptopropionic Acid-Capped AIZS Quantum Dots
} Maroua Mrad, Tahar Ben Chaabane, Hervé Rinnert, Balan Lavinia, Jordane Jasniewski, Ghouti Medjahdi, Raphaël Schneider

\section{- To cite this version:}

Maroua Mrad, Tahar Ben Chaabane, Hervé Rinnert, Balan Lavinia, Jordane Jasniewski, et al.. Aqueous Synthesis for Highly Emissive 3-Mercaptopropionic Acid-Capped AIZS Quantum Dots. Inorganic Chemistry, 2020, 59 (9), pp.6220-6231. 10.1021/acs.inorgchem.0c00347 . hal-02551136

\section{HAL Id: hal-02551136 \\ https://hal.univ-lorraine.fr/hal-02551136}

Submitted on 7 Jan 2021

HAL is a multi-disciplinary open access archive for the deposit and dissemination of scientific research documents, whether they are published or not. The documents may come from teaching and research institutions in France or abroad, or from public or private research centers.
L'archive ouverte pluridisciplinaire HAL, est destinée au dépôt et à la diffusion de documents scientifiques de niveau recherche, publiés ou non, émanant des établissements d'enseignement et de recherche français ou étrangers, des laboratoires publics ou privés. 


\section{Aqueous Synthesis for Highly Emissive 3-}

\section{Mercaptopropionic Acid-Capped AIZS Quantum}

\section{Dots}

Maroua Mrad, ${ }^{,+\neq}$Tahar Ben Chaabane, ${ }^{\dagger}$ Hervé Rinnert,, Lavinia Balan,,${ }^{\perp}$ Jordane Jasniewski,,$"$ Ghouti Medjahdi, ${ }^{\S}$ and Raphaël Schneider ${ }^{*}, \neq$

${ }^{\dagger}$ Université de Carthage, Faculté des Sciences de Bizerte, LR 18 ES11 Laboratoire des composés hétéro-organiques et des matériaux nanostructurés, 7021 Jarzouna, Bizerte, Tunisia

${ }^{\ddagger}$ Université de Lorraine, CNRS, LRGP, F-54000 Nancy

${ }^{\S}$ Université de Lorraine, CNRS, IJL, F-54000 Nancy, France

${ }^{\perp}$ CEMHTI-UPR 3079 CNRS, Site Haute Température, 1D avenue de la Recherche Scientifique, 45071 Orléans, France

" Université de Lorraine, LIBio, F-54000 Nancy, France 


\section{ABSTRACT}

Highly fluorescent and color tunable $\operatorname{AgInS}_{2}(\mathrm{AIS})$ and $\left(\mathrm{AgInS}_{2}\right) \mathrm{x}(\mathrm{ZnS})_{1-\mathrm{x}}$ (AIZS) quantum dots (QDs) were prepared via a facile aqueous-phase synthesis using $\mathrm{AgNO}_{3}, \mathrm{In}\left(\mathrm{NO}_{3}\right)_{3}, \mathrm{Zn}(\mathrm{OAc})_{2}$ and $\mathrm{Na}_{2} \mathrm{~S}$ as precursors and 3-mercaptopropionic acid (3-MPA) as ligand. Produced AIZS QDs exhibit a small diameter (ca. $2.1 \mathrm{~nm}$ ) and a cubic structure. Ag-3-MPA and In-3-MPA complexes formed during the preparation of AIS cores were found to play a key role on the fate of the reaction and an atypical blue-shift of the PL emission was observed with the increase of the $\mathrm{Ag} / \mathrm{In}$ ratio. The photoluminescence quantum yield (PL QY) of AIS QDs is modest but increased markedly after the alloying and shelling with $\mathrm{ZnS}$ (up to 65\%). Size and composition-selective precipitations allowed to separate up to 13 fractions of AIZS QDs with exceptionally high PL QYs (up to 78\%), which is the highest value reported to date for AIZS QDs prepared in aqueous phase. These high PL QYs combined to their good colloidal stability and photostability make AIZS QDs of high potential as cadmium-free fluorescent probes for various applications like bio-imaging or sensing.

\section{INTRODUCTION}

$\mathrm{I}-\mathrm{III}-\mathrm{VI}_{2}$ ternary semiconductor nanocrystals (quantum dots, QDs) have attracted great interest because these QDs are considered as environmentally friendly compared to Cd-based binary QDs. ${ }^{1-7}$ Moreover, their optical properties can be tuned by varying their size and their composition. I-III-VI 2 QDs also exhibit large Stokes shifts which avoid non-radiative Förster 
resonance energy transfer upon photoluminescence (PL) emission and long PL lifetimes (> 100 ns) compared to Cd-based QDs. ${ }^{1-7}$

Among I-III-VI 2 semiconductors, $\mathrm{AgInS}$ (AIS) is a direct bandgap material varying from 1.87 to $2.03 \mathrm{eV}$ depending on its crystalline structure which allows a PL emission from the visible to the near-infrared region. However, the relatively weak PL quantum yields (QYs) of AIS QDs, especially those exhibiting a large diameter and thus a high concentration of surface defects states, restricts their use in applications like biological labeling, solar cells or electroluminescent devices.

To increase PL QYs, a ZnS shell can be installed at the periphery of AIS QDs to create type I heterostructures. The shelling is accompanied by a diffusion of $\mathrm{Zn}^{2+}$ ions in the AIS core followed by a partial cation exchange/alloying process leading to quaternary $\left(\operatorname{Ag} \operatorname{InS} S_{2}\right) x(Z n S)_{1-x}$ QDs, thereafter noted AIZS. ${ }^{8-11}$ The graded composition of AIZS QDs decreases the lattice mismatch between the AIS core and the $\mathrm{ZnS}$ shell and thus favors the production of nanocrystals exhibiting high PL QYs. ${ }^{12}$ A blue-shift of the PL emission spectra is observed during the cationic interdiffusion due to the higher bandgap energy of $\mathrm{ZnS}$ (3.6 eV for the bulk material) compared to AIS QDs. AIS and AIZS exhibit a broad PL emission ascribed to donor-acceptor (D-A) pair recombination in which photo-generated electrons and holes are trapped in deep donor (sulfur vacancies $V_{S}$ and silver interstitial atoms $A g_{\text {int }}$ ) and acceptor levels (silver vacancies $V_{A g}$ and sulfur interstitial atoms $S_{\text {int }}$ ), respectively. ${ }^{13-15}$ The charge carriers radiative recombinations occur via these intragap levels, which accounts for the large Stokes shift observed.

AIS and AIZS are usually prepared in organic medium by the thermal decomposition of organometallic complexes, ${ }^{16,17}$ by heating of metal salts, thiourea and ligands (dodecanethiol, oleylamine) in high boiling point solvents, ${ }^{12,18,19}$ or via the hot-injection method. ${ }^{20,21}$ In recent 
years, aqueous syntheses of AIS and AIZS QDs have also emerged because the dots obtained are dispersible in aqueous media without phase transfer, which facilitates their use for biological applications. These syntheses can be conducted in water at reflux, under hydrothermal conditions or under microwave irradiation. Glutathione (GSH), and GSH associated to cysteamine or sodium citrate are the most commonly used ligands for the preparation of high quality dots. ${ }^{22-29}$ A few reports describe also the use of thioglycolic acid (TGA) or TGA combined with polyacrylic acid, ${ }^{30,31} 3$-mercaptopropionic acid (3-MPA), ${ }^{32}$ mercaptosuccinic acid associated to sodium citrate,$^{33}$ cysteine,$^{34,35} \mathrm{~N}$-acetylcysteine, ${ }^{36}$ poly(ethyleneimine), ${ }^{37,38}$ gelatin, ${ }^{39}$ carboxymethylcellulose, ${ }^{40}$ and chitosan ${ }^{41}$ as capping agents. A cation exchange process using $\mathrm{Ag}_{2} \mathrm{~S}$ QDs as precursors of AIS and AIZS QDs has also been reported. ${ }^{42}$ The PL emission wavelength of AIZS can usually be tuned from 520 to $650 \mathrm{~nm}$ depending on the synthesis conditions. High quality AIZS with PL QYs up to 60\% have been reported using GSH as ligand but PL QYs are more generally between 20 and $40 \%$.

In this work, we developed a facile one-pot two step method for the preparation of 3-MPAcapped AIZS QDs using $\mathrm{AgNO}_{3}, \mathrm{In}\left(\mathrm{NO}_{3}\right)_{3}, \mathrm{Zn}(\mathrm{OAc})_{2}$ and $\mathrm{Na}_{2} \mathrm{~S}$ as precursors. AIZS QDs exhibit PL QYs up to 78\% after size and composition-selective sorting, which is the highest value reported to date for AIZS QDs prepared in aqueous solution, and long PL lifetimes (ca. $300 \mathrm{~ns}$ for the samples with the highest PL QYs). The PL emission is adjustable by changing the Ag/In ratio, the fraction of $\mathrm{Zn}^{2+}$ in AIZS QDs, or the reaction temperature during the synthesis of the dots.

\section{RESULTS AND DISCUSSION}


Synthesis of AIS and AIZS QDs and their optical properties. A one-pot two-steps method was developed for the preparation of AIZS QDs (Figure 1). AIS cores were prepared by solubilizing $\mathrm{Ag}$ and In precursors $\left(\mathrm{nAg}^{+}+\mathrm{nIn}^{3+}=0.5 \mathrm{mmole}\right)$ in $25 \mathrm{~mL}$ of a $0.2 \mathrm{M} 3$-MPA aqueous solution adjusted to $\mathrm{pH} 8.5$, followed the injection of an aqueous solution of $\mathrm{Na}_{2} \mathrm{~S}(0.35$ mmole) and by heating the mixture at $100^{\circ} \mathrm{C}$. A pH increase of the reaction mixture to 9.2 is observed upon the addition of $\mathrm{Na}_{2} \mathrm{~S}$. In preliminary experiments not described here, a gradual decrease of the PL QY with the increase of the amount of $\mathrm{Na}_{2} \mathrm{~S}$ injected was observed (15.6, 11.4, 9.1, 6.9 and $5.5 \%$ using $0.35,0.41,0.5,0.625$ and $0.833 \mathrm{mmol} \mathrm{Na}_{2} \mathrm{~S}$, respectively). Although the preparation of the AIS core is conducted with a sub-stoechiometric amount of $\mathrm{Na}_{2} \mathrm{~S}$, the 3-MPA is an attractive ligand for the aqueous synthesis of QDs since it is well-known to decompose and generate sulfide $\mathrm{S}^{2-}$ ions under UV-light irradiation or prolonged heating. ${ }^{43}$ Moreover, both the thiol and the carboxylate oxygen atoms can coordinate to surface Ag and In atoms to form a stable hexagonal loop. ${ }^{44}$ This bidentate coordination also affects the electronic structure of the QDs with an optimal surface passivation of dangling bonds, for example chalcogenide vacancies responsible of deep trap state emission, and thus allows an improvement of the PL QY. ${ }^{45}$ Control experiments conducted without adding $\mathrm{Na}_{2} \mathrm{~S}$ in the reaction mixture only show a weak PL emission originating from AIS or AIZS QDs. However, the black particles formed during these reactions suggest that gradually formed $\mathrm{S}^{2-}$ react with $\mathrm{Ag}^{+}$ions to form $\mathrm{Ag}_{2} \mathrm{~S}$. These experiments demonstrate that the thermal decomposition of 3-MPA compensates for the defect in $\mathrm{Na}_{2} \mathrm{~S}$ in our synthetic conditions. 


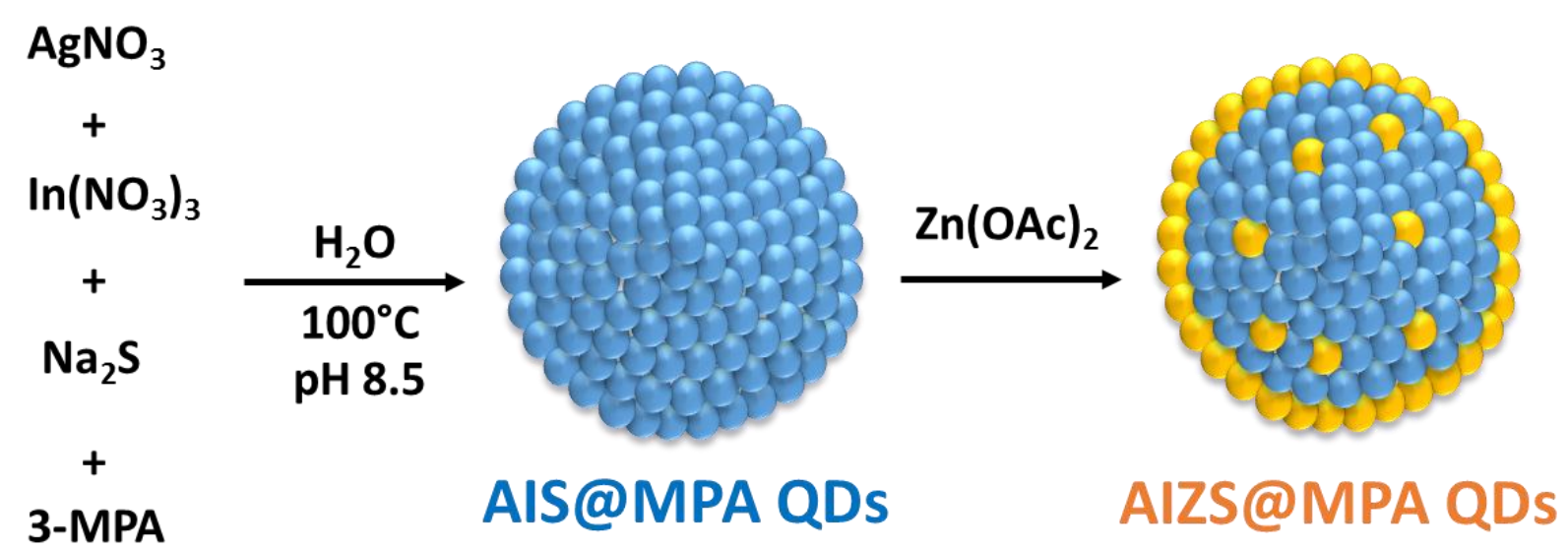

Figure 1. Schematic illustration of AIS and AIZS QDs synthesis in aqueous solution.

Representative UV-visible and PL emission spectra recorded during the preparation of the AIS core $(\mathrm{Ag} / \mathrm{In}=1 / 5)$ are given in Figure 2. As usually observed for I-III-VI 2 QDs, AIS QDs exhibit a wide absorption both in the UV and in the visible regions. ${ }^{19,46}$ Only a broad shoulder without a sharp excitonic peak can be observed. This originates from the distribution of vibrational states due to the inhomogeneities in nanocrystals compositions and not from a wide size distribution (vide infra). The onset of the UV-visible absorption spectra remains almost unchanged during the synthesis, indicating that AIS cores formed quickly upon the injection of $\mathrm{Na}_{2} \mathrm{~S}$ in the reaction medium (Figure 2a). The PL intensity increases over time, reaches its maximum value after 180 min before decreasing (Figure 2b). For QDs prepared with low Ag/In ratios (from 1/60 to 1/3), optimal optical properties are usually obtained after 180 min heating at $100^{\circ} \mathrm{C}$, while lower reaction times (ca. $30 \mathrm{~min}$ ) are required for $\mathrm{Ag} / \mathrm{In}$ ratios of 1/2, 1/1 and 2/1. To obtain AIS QDs emitting at different wavelengths, the $\mathrm{Ag} / \mathrm{In}$ ratio was first varied from 1/60 to 2/1 during the preparation of the AIS cores $\left(n\left(\mathrm{Ag}^{+}+\mathrm{In}^{3+}\right)=0.5 \mathrm{mmol}\right)$ while maintaining the amount of $\mathrm{Na}_{2} \mathrm{~S}$ at 0.35 mmole and the concentration of 3-MPA at $0.2 \mathrm{M}$. Two components peaks can be observed in the PL emission spectra of AIS QDs, the intrinsic trap state emission at wavelengths decreasing from 608 to $577 \mathrm{~nm}$ when increasing the $\mathrm{Ag} / \mathrm{In}$ ratio and a much weaker surface trap- 
state emission located at ca. $639 \mathrm{~nm}$ (Figure S1). Note that the PL spectrum obtained for the $\mathrm{Ag} / \mathrm{In}$ ratio of $2 / 1$ is not provided due to its weak intensity. The blue-shift observed when increasing the $\mathrm{Ag} / \mathrm{In}$ ratio is surprising. Indeed, the valence band of AIS QDs is composed of S $3 \mathrm{p}$ orbitals hybridized with Ag $4 \mathrm{~d}$ orbitals while the conduction band is formed by hybrid In 5p5s and S 3p orbitals. ${ }^{34,47}$ The increase of the nanocrystals Ag content should decrease the bandgap and thus conduct to a red-shift of the PL emission, which is well documented in the literature. ${ }^{30,37,39}$ 

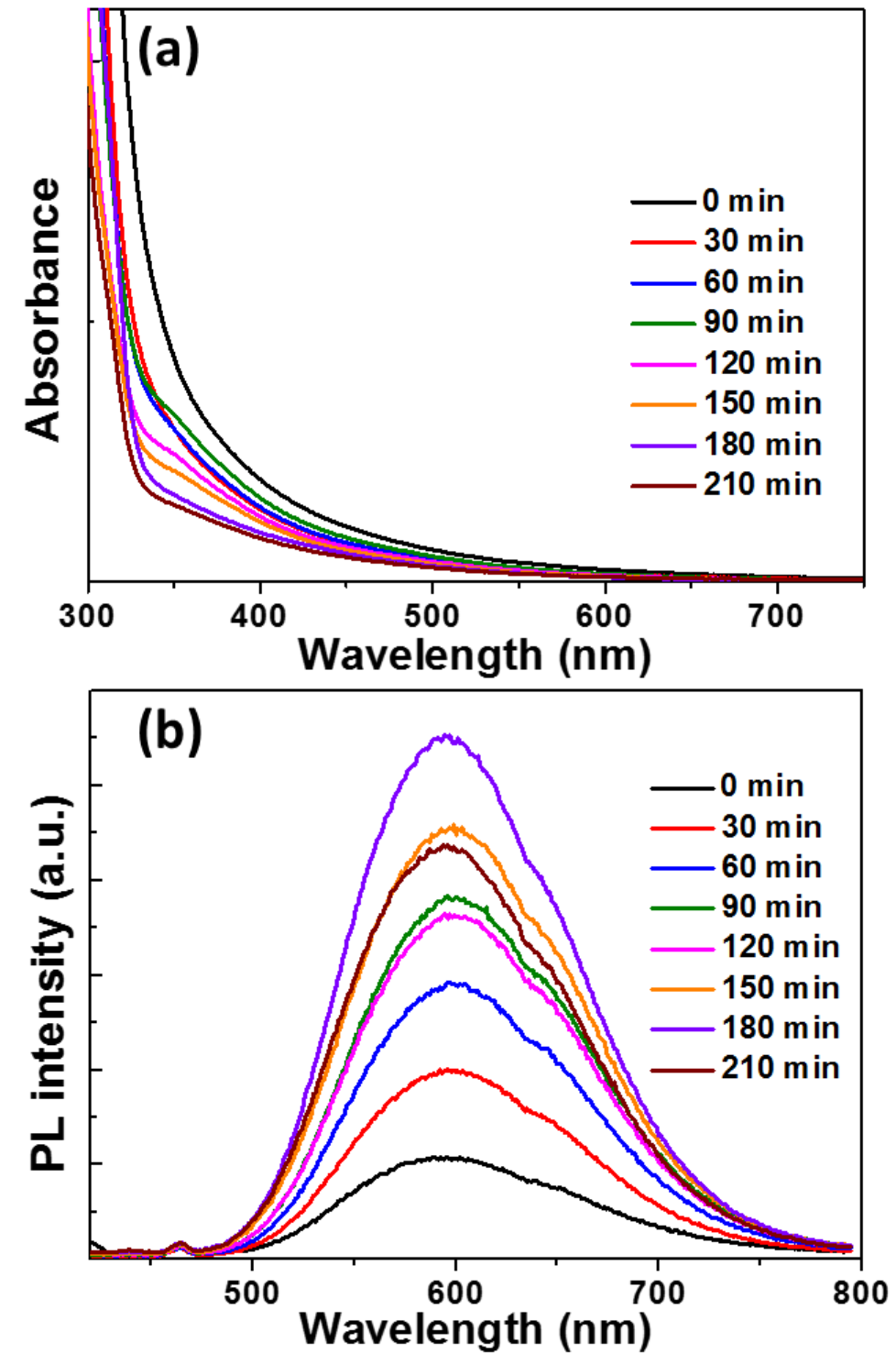

Figure 2. Temporal evolutions of (a) UV-visible absorption and (b) PL emission spectra during the synthesis of AIS cores (reaction conducted at $100^{\circ} \mathrm{C}$ with a $\mathrm{Ag} / \mathrm{In}$ ratio of $1 / 5$ ).

To understand this atypical evolution of AIS QDs PL emission when varying the Ag/In ratio, complementary experiments were first conducted by decreasing the 3-MPA concentration $(0.05$, 0.02 or $0.01 \mathrm{M}$ ) while maintaining the concentrations of $\mathrm{Ag}^{+}$and $\mathrm{In}^{3+}$ (Figure S2a). A redshift of 
the PL emission from 592 to $619 \mathrm{~nm}$ is observed with the decrease of the 3-MPA concentration. This redshift is accompanied by the appearance of a defect-related emission centered at $647 \mathrm{~nm}$, which confirms that the $0.2 \mathrm{M}$ concentration in 3-MPA is optimal to obtain an almost defect-free D-A pair PL emission. Moreover, when fixing the 3-MPA concentration at $0.02 \mathrm{M}$ and varying the $\mathrm{Ag} / \mathrm{In}$ ratio $(1 / 60,1 / 15$ or $1 / 5)$, the classically observed redshift of the PL emission with the increase of the Ag content of the nanocrystals is observed (Figure S2b). These results clearly demonstrate that the 3-MPA concentration plays a key role on the blue-shift of the PL emission described in Figure S1 and thus on the growth of AIS QDs.

At $\mathrm{pH}$ 8.5, 3-MPA is present in its carboxylate form $\left(\mathrm{pK}_{\mathrm{COOH}}=4.32\right)$ and the thiol function is not deprotonated $\left(\mathrm{pK}_{\mathrm{SH}}=10.20\right)$. As the thiol function of 3-MPA coordinates to $\operatorname{In}^{3+}$ more strongly that the carboxylate function, $\mathrm{In}^{3+}$ was demonstrated to form $\mathrm{InL}_{4}{ }^{2-}$ complexes with 3MPA (complex 1, Figure 3). ${ }^{48} \mathrm{Ag}^{+}$is a soft acid according to the Pearson theory and can also easily form complexes with thiol containing molecules like $\mathrm{AgL}_{2}^{-}$chelates that have been evidenced at $\mathrm{pH}$ values higher than 5 using sulfur-containing aminoacids, suggesting that complex 2 may likely be present in the reaction medium as $\mathrm{Ag}^{+}$precursor (Figure 3). ${ }^{49}$ The formation of such complexes can be observed by the changes in the UV-visible absorption spectra of $\mathrm{AgNO}_{3}$ and $\mathrm{In}\left(\mathrm{NO}_{3}\right)_{3}$ when using water or the $0.2 \mathrm{M}$ 3-MPA solution as solvents (Figure S3). Our results show that such complexes and/or coordination polymers may form between $\mathrm{Ag}^{+}, \mathrm{In}^{3+}$ and 3-MPA in our synthetic conditions and that $\mathrm{Ag}^{+}$ions in these complexes likely exhibit a lower reactivity than solvated $\mathrm{Ag}^{+}$ions which delays their reaction with $\mathrm{S}^{2-}$ anions and thus their incorporation into AIS cores. 


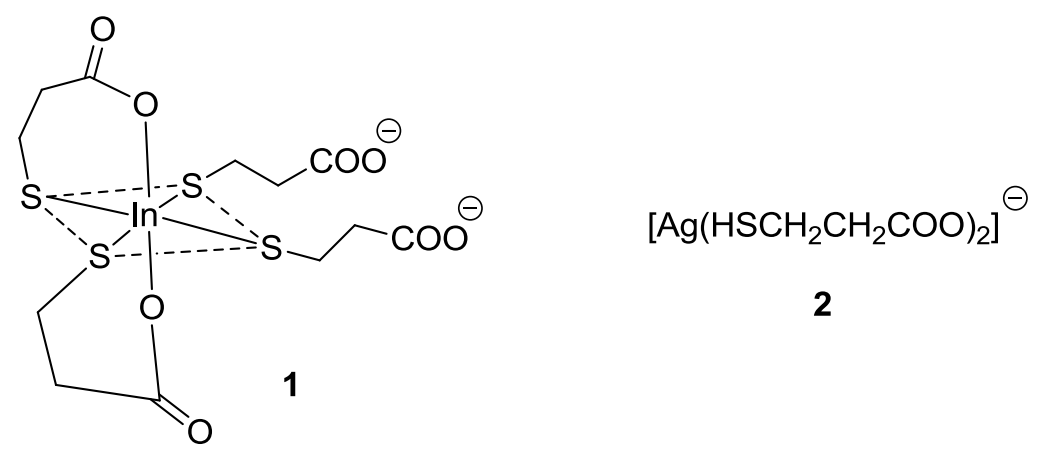

Figure 3. Structures of complexes 1 and 2 likely formed between 3-MPA and $\mathrm{In}^{3+}$ and $\mathrm{Ag}^{+}$, respectively.

In the second step of the synthesis, $\mathrm{Zn}(\mathrm{OAc})_{2}(1 \mathrm{mmol})$ is injected in the AIS QDs solution and the mixture stirred for ca. 120 min at reflux. Upon addition of the $\mathrm{Zn}(\mathrm{OAc})_{2}$, the $\mathrm{pH}$ decreases to 6.3 due to the consumption of the hydroxyl anions by the hydrolysis of the $\mathrm{Zn}$ precursor. The slight red-shift of the UV-visible absorption spectra suggests that $\mathrm{Zn}^{2+}$ ions do not only diffuse into the AIS cores but also that a ZnS shell is formed at the periphery of AIZS QDs yielding core/shell AIZS/ZnS nanocrystals (Figure 4a and the inset). For AIZS QDs prepared with a $\mathrm{Ag} / \mathrm{In}$ ratio of 1/5, a blue-shift from ca. 600 to $533 \mathrm{~nm}$ is immediately observed after adding the Zn precursor, indicating the successful displacement of $\mathrm{Ag} 4 \mathrm{~d}$ orbitals due to the diffusion of $\mathrm{Zn}^{2+}$ ions in the AIS cores (Figure $4 \mathrm{~b}$ ). 

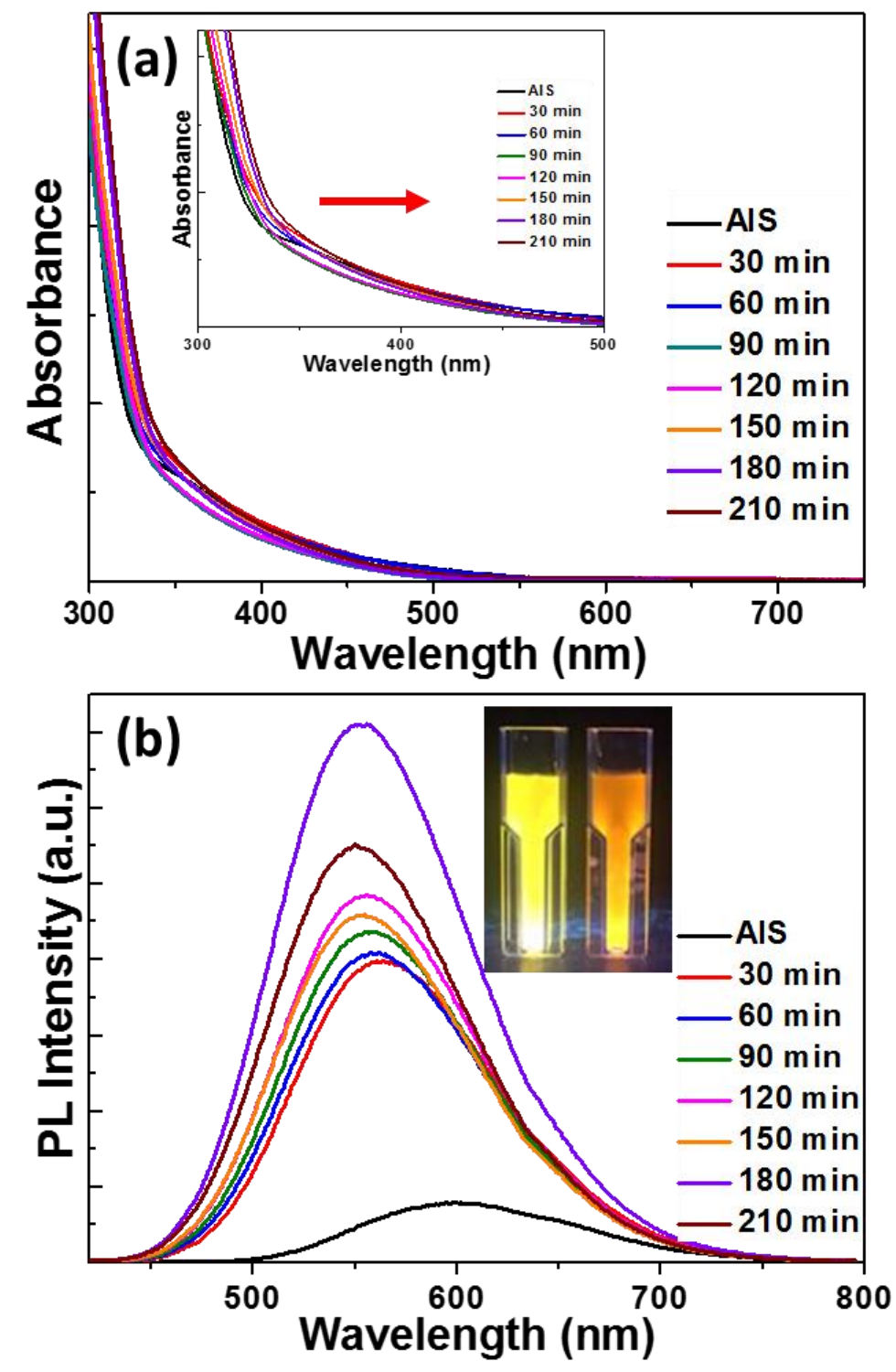

Figure 4. Temporal evolutions of (a) UV-visible absorption and (b) PL emission spectra during the synthesis of AIZS QDs $(\mathrm{Ag} / \mathrm{In}$ ratio of $1 / 5)$. The inset of (a) is a magnification of the absorption spectra showing the red-shift observed during the synthesis of AIZS QDs and the inset of (b) is a digital photograph taken under UV light illumination of AIS and AIZS QDs. 
Figure 5 shows the optical properties of AIZS QDs when varying the Ag/In ratio. As previously, the UV-visible absorption spectra do not exhibit any prominent peak due to the internal gradient composition (Figure 5a). ${ }^{19,46}$ The blue-shift of the PL emission spectra observed for AIS QDs with the increase of the Ag/In ratio is reflected in the AIZS QDs and the PL emission is ranging from 571 to $546 \mathrm{~nm}$ when the $\mathrm{Ag} / \mathrm{In}$ ratio is varied from 1/60 to 2/1 (Figure 5b). The surface trap-state emission disappears after the alloying and shelling with $\mathrm{ZnS}$ and the full-width at half-maximum (FWHM) of PL emission spectra is ca. $110 \mathrm{~nm}$ and a large Stokes shift is observed between the UV-visible absorption and the PL emission. The PL QY of the AIS cores is modest likely due to the high density of non-radiative surface defects (the highest values, 9-15\%, were measured for the dots prepared with $\mathrm{Ag} / \mathrm{In}$ ratios of 1/15, 1/5, 1/3 and 1/2). Upon alloying and shelling with ZnS, PL QYs increased markedly due to the effective passivation of AIZS core with the wide bandgap ZnS shell (relative PL QYs of 61, 65, 63 and 61\% were measured for AIZS QDs prepared with Ag/In ratios of $1 / 15,1 / 5,1 / 3$ and $1 / 2$, respectively) ${ }^{50}$ The absolute PL QYs agree reasonably with the relative PL QYs (54, 57, 54 and 56\% for AIZS QDs prepared with $\mathrm{Ag} / \mathrm{In}$ ratios of $1 / 15,1 / 5,1 / 3$ and $1 / 2$, respectively) considering that absolute PL QYs were measured with an intense excitation light source $(450 \mathrm{~W})$ and that uncertainties varying between 5 and 10\% may be reached for the determination of PL QYs. ${ }^{51}$ The high PL QYs determined for AIZS QDs likely result from the high density of the 3-MPA ligand at their surface (vide infra) and from the effective passivation of surface states by the $\mathrm{ZnS}$ shell that suppresses the non-radiative recombination transitions.

The optical bandgap $(E g)$ of AIZS QDs was determined from the Tauc plots of $(\alpha h v)^{2}$ vs hv, where $\alpha$ is the absorption coefficient, $\mathrm{h}$ is the Planck's constant and $v$ is the light frequency (Figure 5c). The bandgap was found to expand from 2.15 to $2.73 \mathrm{eV}$ when increasing the $\mathrm{Ag} / \mathrm{In}$ 
ratio from $1 / 60$ to $2 / 1$, which is coherent with the previously described optical properties of AIS cores.
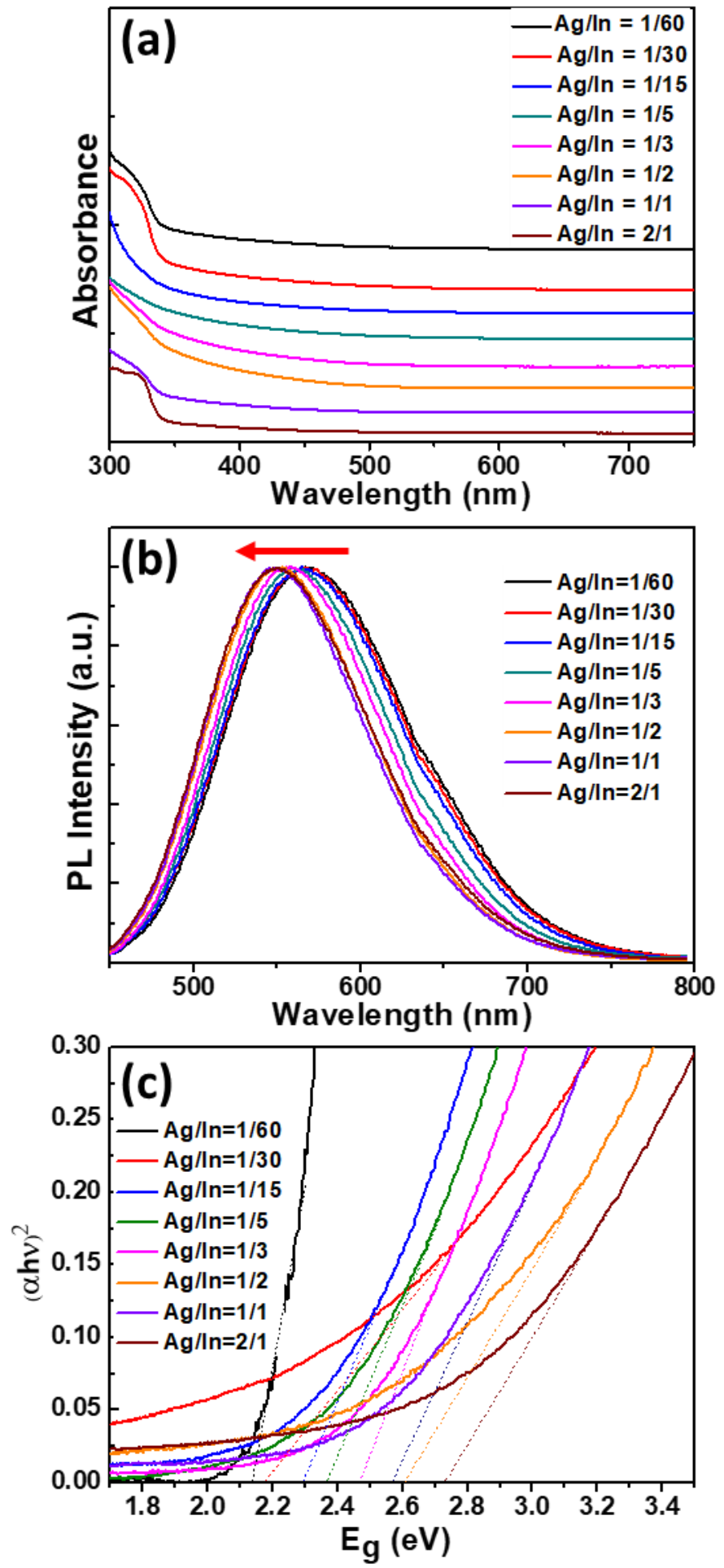
Figure 5. (a) UV-visible absorption and (b) normalized PL emission spectra of AIZS QDs when varying the Ag/In ratio from 1/60 to 2/1. (c) Determination of the optical bandgap of AIZS QDs from extrapolating the linear portion of the plot of $(\alpha h v)^{2} v s h v$.

The PL emission wavelength of AIZS QDs can be tuned by varying the amount of $\mathrm{Zn}(\mathrm{OAc})_{2}$ injected after the preparation of the AIS core (Figure 6a). Using AIS QDs emitting at $612 \mathrm{~nm}$ $(\mathrm{Ag} / \mathrm{In}=1 / 5)$, the PL emission wavelength gradually blue-shifts from 586 to $558 \mathrm{~nm}$ with the increase of $\mathrm{Zn}(\mathrm{OAc})_{2}$ added, which confirms a higher loading in $\mathrm{ZnS}$ in $\left(\mathrm{AgInS}_{2}\right)_{\mathrm{x}}(\mathrm{ZnS})_{1-\mathrm{x}}$ nanocrystals. These results indicate that the synthetic process developed allows the preparation of AIZS QDs emitting at the desired wavelength simply by controlling the bandgap energy of the nanocrystals via the amount of $\mathrm{Zn}(\mathrm{OAc})_{2}$ added.

The temperature also influences the kinetic of the $\mathrm{ZnS}$ alloying process. Starting from AIS QDs emitting at $626 \mathrm{~nm}(\mathrm{Ag} / \mathrm{In}=1 / 15)$ and injecting $1 \mathrm{mmol}$ of $\mathrm{Zn}(\mathrm{OAc})_{2}$, AIZS QDs emitting at $605 \mathrm{~nm}$ were prepared at 40 or $60^{\circ} \mathrm{C}$ while the blue-shift is significantly more pronounced (emission at ca. $555 \mathrm{~nm}$ ) when conducting the reaction at 80 or $100^{\circ} \mathrm{C}$ (Figure 6b). Noteworthy is also the marked decrease of the FWHM of the PL emission spectra (ca. $145 \mathrm{~nm}$ for reactions conducted at 40 or $60^{\circ} \mathrm{C}$ vs $110 \mathrm{~nm}$ for reactions performed at 80 or $100^{\circ} \mathrm{C}$ ). 

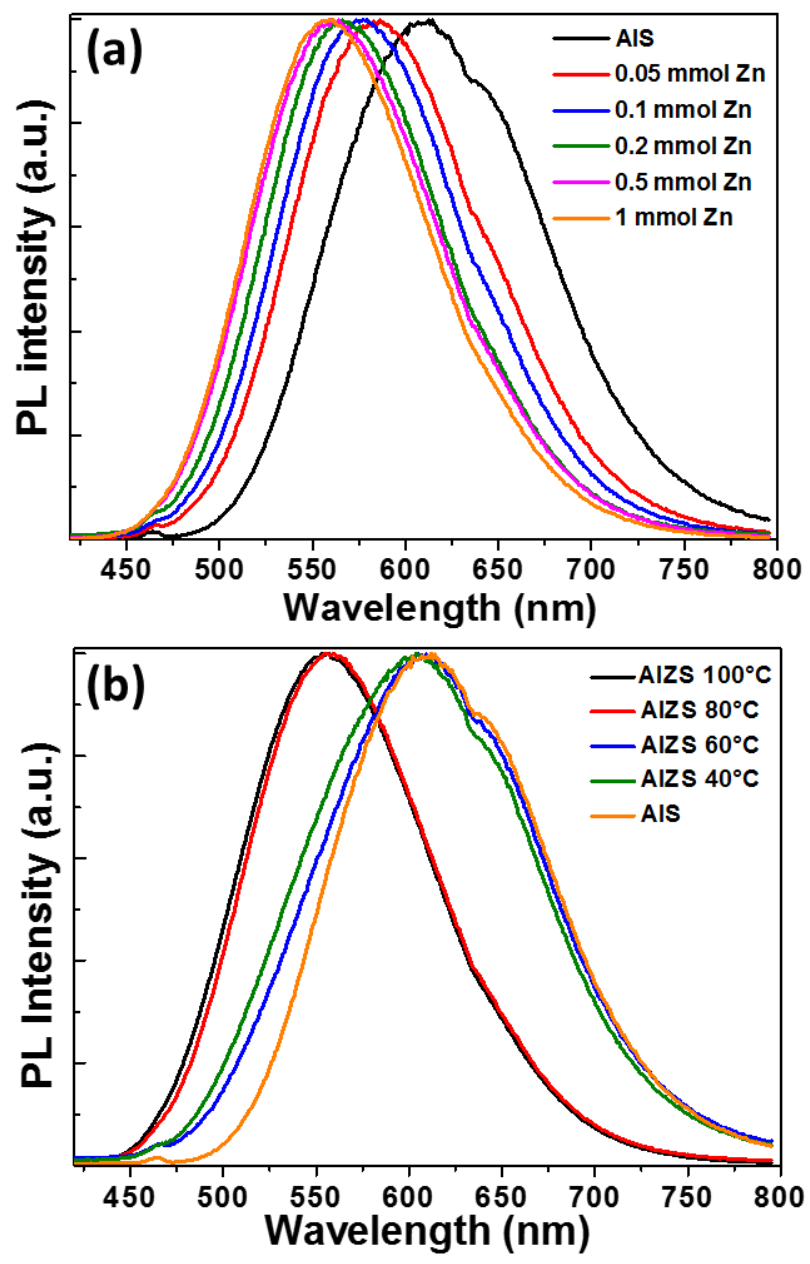

Figure 6. Influence of (a) the amount of $\mathrm{Zn}$ precursor added and (b) the temperature on the PL emission maxima of AIZS QDs prepared with a Ag/In ratio of 1/15. Normalized PL emission spectra are provided in the figure.

The influence of the Ag/In ratio used during the synthesis of the dots on the mechanism of the PL emission was also investigated via time-resolved PL measurements. The time-resolved PL measurements were recorded at the wavelengths corresponding to the PL emission maxima of AIZS QDs (see Figure 5b). The obtained results were best fitted using a bi-exponential function $I(t)=A_{1} \exp \left(-t / \tau_{1}\right)+A_{2} \exp \left(-t / \tau_{2}\right)$ where $\tau_{1}$ and $\tau_{2}$ are the decay time constants of the PL and $A_{1}$ and $\mathrm{A}_{2}$ the amplitudes of the components. Results are shown in Figure 7 and Table 1. As 
previously observed for AIZS QDs, the PL decay curves could be decomposed into two components. ${ }^{19}$ The fast decay component $\tau_{1}$ corresponds to surface trap states (dangling bonds or vacancies) and the slow decay component $\tau_{2}$ to the D-A recombination originating from the intragap defect states. The $A_{1} / A_{2}$ ratio is the lowest (ca. 0.45) for the $A g / I n$ ratio of $1 / 5$, indicating that electrons and holes mainly recombine via the D-A states in these QDs. This result is in good agreement with the high PL QY (65\%) measured for these nanocrystals. The average PL lifetimes $\left(\tau_{\text {av }}\right)$ were determined using $\tau_{\text {av }}=\left(\mathrm{A}_{1} \tau_{1}+\mathrm{A}_{2} \tau_{2}\right) /\left(\mathrm{A}_{1}+\mathrm{A}_{2}\right)$ and are of ca. $0.3 \mu \mathrm{s}$ regardless of the $\mathrm{Ag} / \mathrm{In}$ ratio used. The long PL lifetimes originate from the numerous intrinsic trap states $\left(\mathrm{V}_{\mathrm{S}}\right.$ and $\mathrm{Ag}_{\mathrm{int}}$ acting as donors while $\mathrm{V}_{\mathrm{Ag}}$ and $\mathrm{S}_{\mathrm{int}}$ as acceptors) and clearly differentiate AIZS QDs from II-VI QDs like CdSe or CdTe that exhibit a short PL lifetime of tens of nanoseconds originating from bandgap emission..$^{19,27,52-54}$

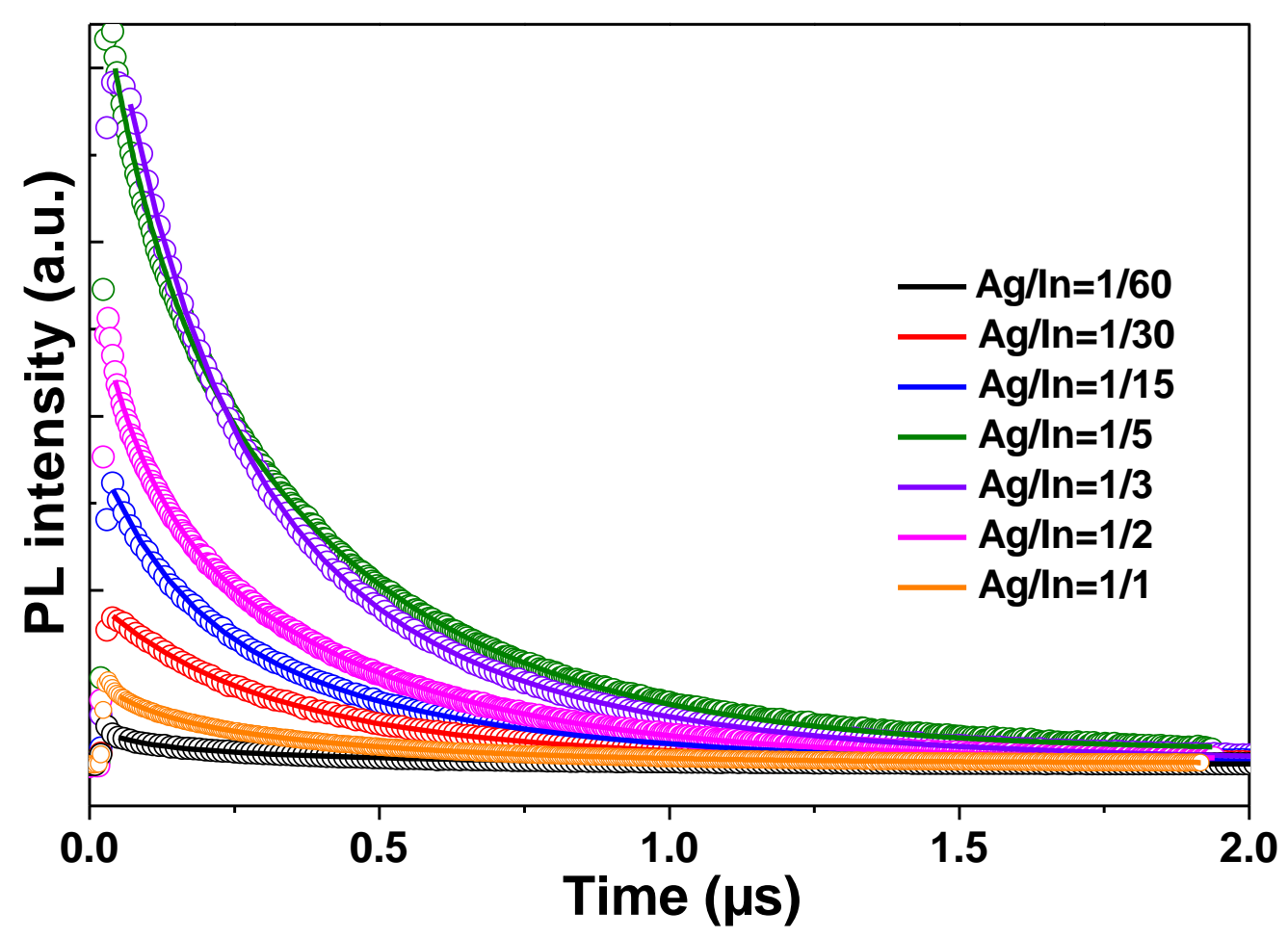

Figure 7. PL decay curves of AIZS QDs in aqueous solution when varying the Ag/In ratio. PL decay curves were measured at the maximum of the PL emission signals (see Figure 4b). 
Table 1. Lifetimes and fitting results for AIZS QDs prepared with different Ag/In ratios.

\begin{tabular}{llllll}
\hline $\begin{array}{l}\mathrm{Ag} / \mathrm{In} \\
\text { ratio }\end{array}$ & $\mathrm{A}_{1}$ & $\begin{array}{l}\tau_{1} \\
(\mu \mathrm{s})\end{array}$ & $\mathrm{A}_{2}$ & $\begin{array}{l}\tau_{2} \\
(\mu \mathrm{s})\end{array}$ & $\begin{array}{c}\tau_{\mathrm{av}} \\
(\mu \mathrm{s})\end{array}$ \\
\hline $1 / 60$ & 0.00189 & 0.0736 & 0.00235 & 0.424 & 0.268 \\
$1 / 30$ & 0.0110 & 0.225 & 0.00843 & 0.567 & 0.374 \\
$1 / 15$ & 0.0167 & 0.122 & 0.0212 & 0.4407 & 0.300 \\
$1 / 5$ & 0.0303 & 0.0856 & 0.0674 & 0.396 & 0.300 \\
$1 / 3$ & 0.0578 & 0.164 & & & 0.290 \\
$1 / 2$ & 0.0211 & 0.0796 & 0.0439 & 0.457 & 0.278 \\
$1 / 1$ & 0.0353 & 0.0812 & 0.0352 & 0.396 & \\
& & & 0.0656 & 0.396 & 0.286 \\
\hline
\end{tabular}

The influence of the $\mathrm{pH}$ on the PL emission of AIZS@MPA QDs was also investigated (Figure S4). Solutions of $0.1 \mathrm{M} \mathrm{HCl}$ or $\mathrm{NaOH}$ were used to adjust the $\mathrm{pH}$. From $\mathrm{pH} 3$ to 10 , the PL intensity is only weakly affected by the $\mathrm{pH}$ and remains almost stable, the highest intensity being observed at $\mathrm{pH}$ 8. A marked decrease of the PL intensity accompanied by a red-shift of the PL emission from 553 to $566 \mathrm{~nm}$ is observed at $\mathrm{pH}$ values higher than 11 . The observed decrease likely originates from a destruction of the $\mathrm{ZnS}$ shell due to the association of hydroxide anions with $\mathrm{Zn}^{2+}$ cations present at the surface of the dots to form $\mathrm{Zn}(\mathrm{OH})_{2}$. Below $\mathrm{pH}$ 3, the dots aggregate and precipitate in the aqueous solution due to the protonation of the 3-MPA ligand $(\mathrm{pKa}=4.32)$. 
The photostability of AIZS QDs prepared with Ag/In ratios of 1/5 and 1/2 was also studied. For that purpose, aqueous dispersions of the dots were irradiated with a $\mathrm{Hg}$-Xe lamp (intensity of $100 \mathrm{~mW} / \mathrm{cm}^{2}$ ) and the evolution of the UV-visible absorption and of the PL emission were monitored over $1 \mathrm{~h}$ (Figure S5). For both QDs, a significant increase of the PL intensity is observed over time (up to 2.5-fold for AIZS QDs prepared with 1/2 Ag/In ratio, Figure S5a,b,e) indicating that $\mathrm{S}^{2-}$ anions generated by the photo-induced decomposition of 3 -MPA and $\mathrm{Zn}^{2+}$ cations present at the surface of the dots create an extra $\mathrm{ZnS}$ shell that improves the efficiency of the D-A pair recombination. This is confirmed by the slight red-shift of the UV-visible absorption to higher wavelengths (Figure S5c,d).

Characterization of AIZS QDs. The Fourier-transform infrared absorption (FT-IR) spectrum of pure 3-MPA exhibits a broad band centered at $3037 \mathrm{~cm}^{-1}$ (O-H stretching), two signals at 2945 and $2906 \mathrm{~cm}^{-1}$ (C-H stretching), two peaks at 2664 and $2567 \mathrm{~cm}^{-1}$ (S-H stretching) and bands at 1699 and $1403 \mathrm{~cm}^{-1}$ (asymmetric and symmetric stretching modes of the $\mathrm{CO}_{2} \mathrm{H}$ function) (Figure S6). The disappearance of the $\mathrm{S}-\mathrm{H}$ stretching confirms that 3-MPA is bounded to $\mathrm{Zn}$ atoms present at the surface of AIZS QDs via the thiol function. The asymmetric and the symmetric vibrations of the carboxylate $\mathrm{CO}_{2}^{-}$group appear at 1553 and $1395 \mathrm{~cm}^{-1}$ for AIZS QDs, respectively.

The chemical state and the elemental composition of AIZS QDs were also analyzed by X-ray photoelectron spectroscopy (XPS). The overview spectrum of AIZS QDs $(\mathrm{Ag} / \mathrm{In}=1 / 5)$ selected as representative shows only the presence of $\mathrm{Ag}, \mathrm{In}, \mathrm{Zn}, \mathrm{S}, \mathrm{C}, \mathrm{O}$ and $\mathrm{Na}$ elements and no impurities were detected (Figure 8a). The two signals observed at 367.91 and 373.87 eV with a split orbit of $5.96 \mathrm{eV}$ in the $\mathrm{Ag}$ high resolution spectrum correspond to $\mathrm{Ag} 3 \mathrm{~d}_{5 / 2}$ and $\mathrm{Ag} 3 \mathrm{~d}_{3 / 2}$ (Figure 8b). ${ }^{55,56}$ The In $3 \mathrm{~d}_{5 / 2}$ and In $3 \mathrm{~d}_{3 / 2}$ peaks appear at 444.99 and $452.48 \mathrm{eV}$, values in good 
accordance with $\operatorname{In}^{3+}$ (Figure $8 \mathrm{c}$ ). ${ }^{55,56}$ The $\mathrm{Zn} 2 \mathrm{p}_{3 / 2}$ signal is observed at $1021.71 \mathrm{eV}$ (Figure 8d) ${ }^{55,56}$ Finally, the $\mathrm{S} 2 \mathrm{p}_{3 / 2}$ peak can be deconvoluted into two signals at 161.83 and $163.03 \mathrm{eV}$ corresponding to $\mathrm{S}$ in the AIZS core and $\mathrm{S}$ of the MPA ligand, respectively (Figure 8e) ${ }^{55-57}$ All these data confirm that the valence states of the elements are $\mathrm{Ag}^{+}, \mathrm{In}^{3+}, \mathrm{Zn}^{2+}$ and $\mathrm{S}^{2-}$. 

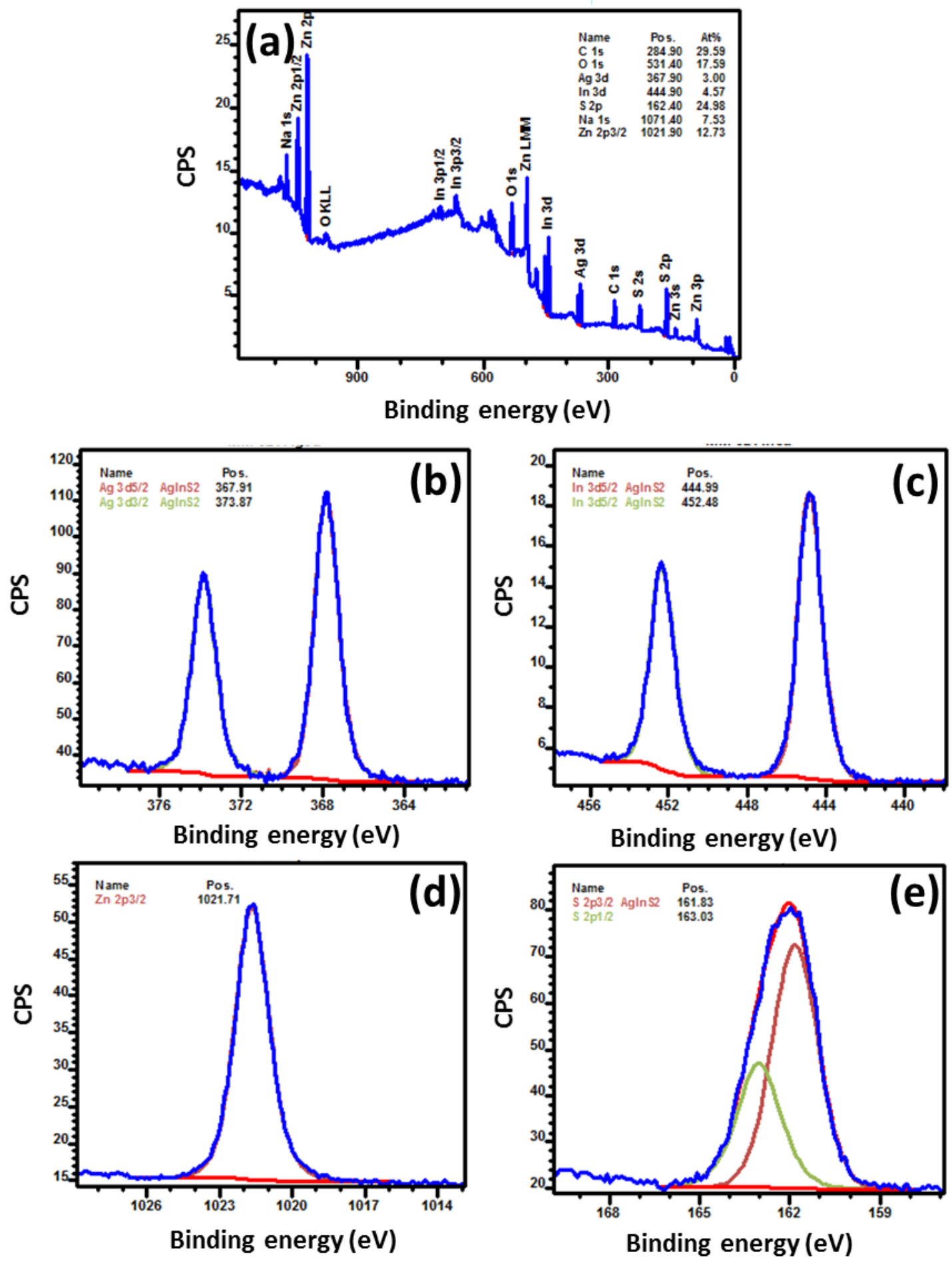

Figure 8. (a) Overview spectrum and high resolution XPS spectra of (b) Ag 3d, (c) In 3d, (d) Zn $2 p$ and (e) S 2p for AIZS QDs prepared with Ag/In ratio of 1/5. 
Representative transmission electron microscopy (TEM) and HR-TEM images of AIZS QDs prepared with Ag/In ratios of 1/15 and 1/5 are given in Figure 9. The QDs exhibit a quasispherical morphology and are well dispersed (Figures 9a and b). The average size of all AIZS QDs prepared was determined to be of ca. $2.1 \mathrm{~nm}$, indicating that changes in the precursor ratios did not markedly influence the size of the nanocrystals (insets of Figures 9a and b). The clear and continuous lattice fringes observed in the high resolution TEM (HR-TEM) images confirm the high crystallinity of AIZS QDs and further confirm the coherent epitaxial growth of the ZnS shell around the AIZS core (Figures 9c and d). The interplanar distance between adjacent lattice planes is $0.31 \mathrm{~nm}$, which corresponds to the (111) crystal plane of cubic ZnS. The associated selected area electron diffraction (SAED) patterns show broad and diffuse rings typical of nanoparticles (insets of Figure 9a and b) and are in good agreement with the cubic phase. Finally, the presence of $\mathrm{Ag}, \mathrm{In}, \mathrm{Zn}$ and $\mathrm{S}$ elements in the AIZS QDs was observed in TEM-associated energy dispersive X-ray spectroscopy (EDS) analyses (Figure S7). 

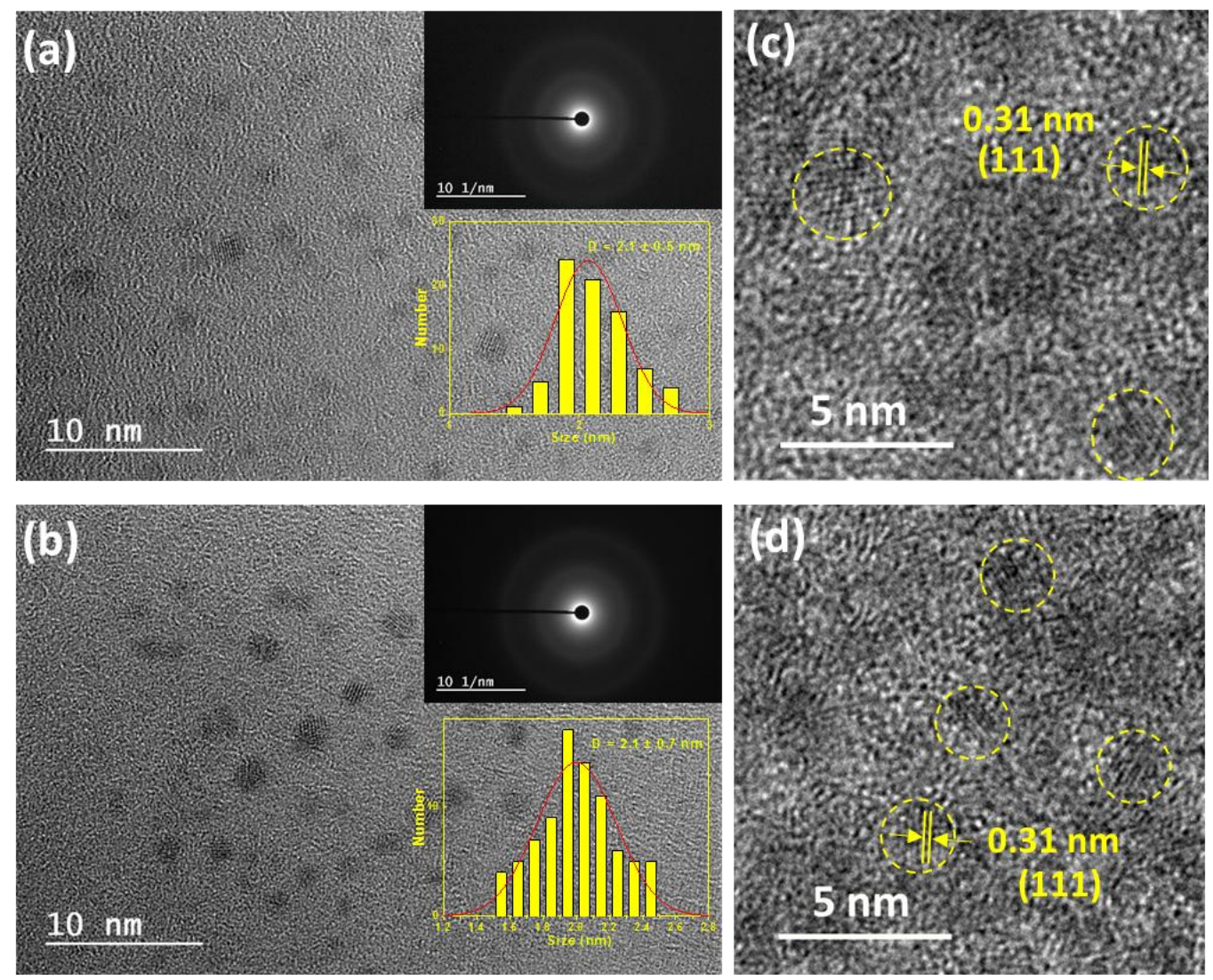

Figure 9. TEM and HR-TEM images of AIZS QDs prepared with Ag/In ratios of (a and c) 1/15 and (b and d) 1/5. The insets of (a) and (b) show the SAED patterns and the particles size distributions.

The crystallinity of AIZS QDs was further confirmed by XRD analyses. Representative XRD patterns of AIS and AIZS QDs prepared with a $\mathrm{Ag} / \mathrm{In}$ ratio of 1/5 are shown in Figure 10a (see Figure S8 for XRD patterns of AIZS QDs with Ag/In ratios of 2/1, 1/2, 1/3, 1/5 and 1/15). The broad diffraction peaks originate from the small size of the nanocrystals. The XRD pattern of AIS QDs exhibits three peaks at $2 \Theta$ values of $26.45,44.30$ and $52.48^{\circ}$ corresponding to (112), (204) and (312) planes of tetragonal $\mathrm{AgInS}_{2}$ (JCPDS No 01-075-0117). Upon diffusion of $\mathrm{Zn}^{2+}$ in the AIS core, a shift toward higher angles, almost at the same position than those of $\mathrm{ZnS}$, is observed. The XRD pattern of AIZS QDs fits well with that of cubic ZnS (see Figure S9 for the 
experimental and calculated data using a lattice constant a of $0.5399 \mathrm{~nm}$ ). This indicates a decrease of the lattice parameters due to the smaller ionic radius of $\mathrm{Zn}^{2+}(0.06 \mathrm{~nm})$ compared to $\mathrm{Ag}^{+}(0.1 \mathrm{~nm})$ and $\mathrm{In}^{3+}(0.062 \mathrm{~nm})$ and thus the formation of an alloy containing $\mathrm{Ag}, \mathrm{In}, \mathrm{Zn}$ and $\mathrm{S}$ elements simultaneously with the deposition of a $\mathrm{ZnS}$ shell at the surface of the AIZS core. ${ }^{37}$ The average size of the dots was estimated to be $3 \pm 1 \mathrm{~nm}$ using the Scherrer equation, which is in good agreement with TEM results. Finally, no impurities were detected in all XRD patterns excepted for AIZS QDs prepared with the 2/1 Ag/In ratio that contain small amounts of $\mathrm{Ag}_{2} \mathrm{~S}$ (Figure S8).

The small sizes of AIZS QDs dispersed in water were confirmed by dynamic light scattering (DLS). For example, Figure 10b shows DLS data for AIZS QDs prepared with a Ag/In ratio of 1/5. The hydrodynamic diameter of the dots (expressed in number) is of $13.5 \pm 2 \mathrm{~nm}$, with a polydispersity index (PDI) of ca. 0.2. This value is higher than that determined by TEM, due to the hydration corona at their periphery. The surface charge is almost similar for all the nanocrystals prepared $(-44 \pm 3.2 \mathrm{mV})$ due to the high density of the negatively-charged 3-MPA ligand at their periphery (Figure 10c), which indicates a high colloidal stability. Aqueous dispersions of AIZS@MPA QDs remain stable for a least 6 months under ambient conditions and were not prone to aggregation. 

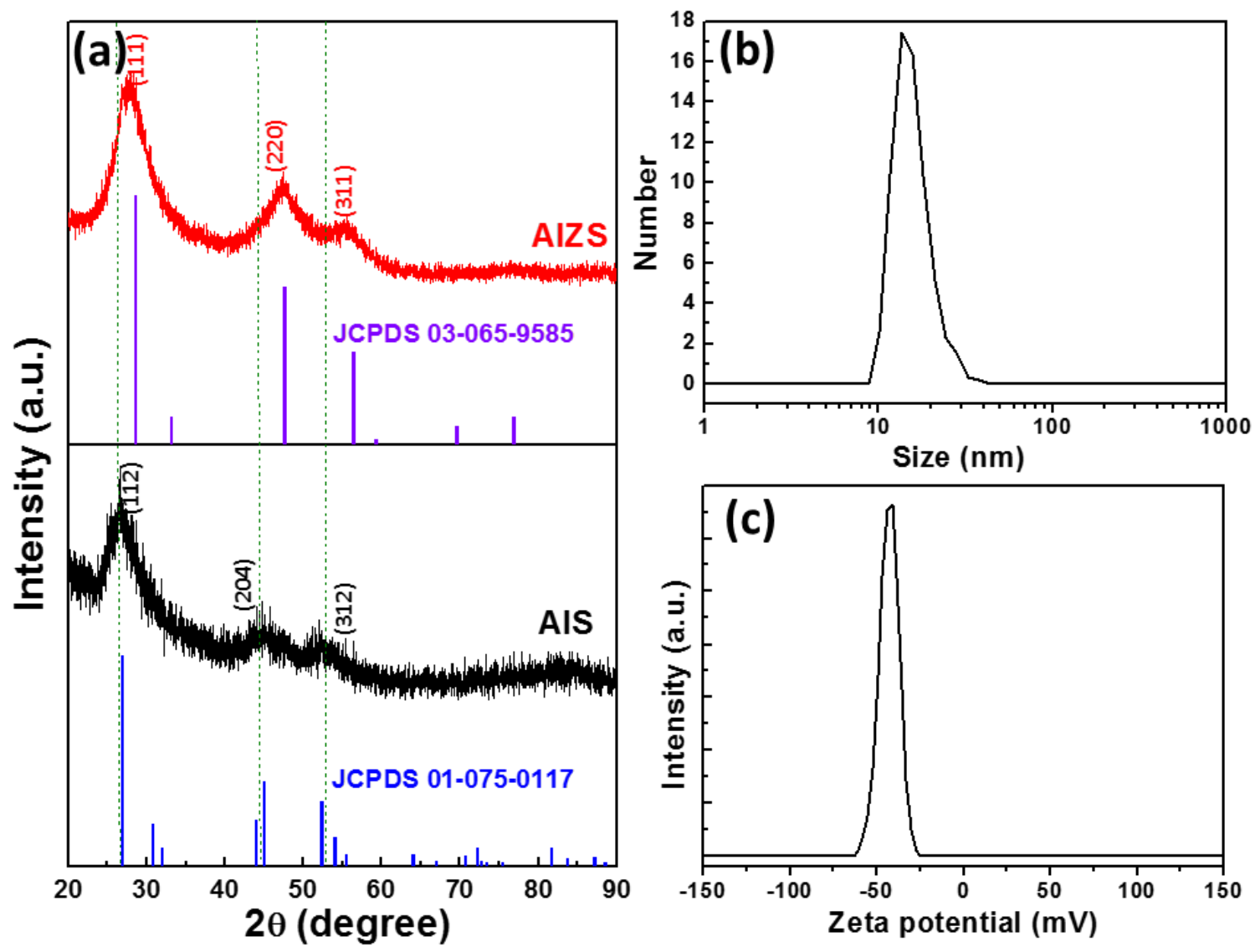

Figure 10. (a) XRD patterns of AIS and AIZS QDs $(\mathrm{Ag} / \mathrm{In}=1 / 5)$, (b) hydrodynamic diameter at $20^{\circ} \mathrm{C}$ of AIZS@MPA QDs determined by DLS and (c) their Zeta potential. DLS and Zeta potential measurements (mean \pm s.d.) originate from $\mathrm{N}=3$ experiments.

Finally, the composition of AIZS QDs was determined based on XPS and EDS analyses (see Table 2 for the results normalized to the Ag element). The final stoichiometry was found to be significantly different from the $\mathrm{Ag} / \mathrm{In} / \mathrm{Zn}$ ratio used for the synthesis. Regardless of the metal ratio used for the synthesis, an excess of S (ca. 25\%) compared to the total amount of metal cations (ca. 20\%) is detected in all AIZS QDs because this element is present both in the core and in the 3-MPA capping ligand. For all QDs, the $\mathrm{Zn} /(\mathrm{Ag}+\mathrm{In})$ ratio is ca. of 2, value in accordance with the ratio used for the synthesis. However, the $\mathrm{Ag} / \mathrm{In}$ ratio is higher than the 
precursor ratio, suggesting that $\mathrm{Zn}^{2+}$ cations preferably substitute $\mathrm{In}^{3+}$ rather than $\mathrm{Ag}^{+}$in the AIZS crystal lattice.

Table 2. Theoretical and actual compositions of AIZS QDs determined by EDX and XPS analyses.

\begin{tabular}{lll}
\hline $\mathrm{Ag} / \mathrm{In}$ ratio & Theoretical composition & Experimental composition \\
\hline $1 / 30$ & $\mathrm{Ag}_{1} \mathrm{In}_{30} \mathrm{Zn}_{64}$ & $\mathrm{Ag}_{1} \mathrm{In}_{0.74} \mathrm{Zn}_{3.21}$ \\
$1 / 15$ & $\mathrm{Ag}_{1} \mathrm{In}_{15} \mathrm{Zn}_{32}$ & $\mathrm{Ag}_{1} \mathrm{In}_{0.71} \mathrm{Zn}_{1.97}$ \\
$1 / 5$ & $\mathrm{Ag}_{1} \mathrm{In}_{5} \mathrm{Zn}_{12}$ & $\mathrm{Ag}_{1} \mathrm{In}_{1.12} \mathrm{Zn}_{1.65}$ \\
$1 / 3$ & $\mathrm{Ag}_{1} \mathrm{In}_{3} \mathrm{Zn}_{8}$ & $\mathrm{Ag}_{1} \mathrm{In}_{0.96} \mathrm{Zn}_{1.34}$ \\
$1 / 1$ & $\mathrm{Ag}_{1} \mathrm{In}_{1} \mathrm{Zn}_{4}$ & $\mathrm{Ag}_{1} \mathrm{In}_{1.21} \mathrm{Zn}_{1.88}$ \\
$2 / 1$ & $\mathrm{Ag}_{1} \mathrm{In}_{0.5} \mathrm{Zn}_{3}$ & $\mathrm{Ag}_{1} \mathrm{In}_{0.52} \mathrm{Zn}_{2.88}$ \\
\hline
\end{tabular}

Size and composition-selection of AIS and AIZS QDs and their optical properties. A sizeselective precipitation was conducted by the addition of a non-solvent, ethanol, to the crude mixture of AIS QDs dispersed in water. As soon as turbidity appeared, the supernatant and the precipitate were separated by centrifugation. This operation was repeated until no fluorescence could be detected in the supernatant. As the sedimentation of nanocrystals in a liquid depends among others on their size and structure, each precipitate should contain AIS QDs with narrower size and composition distributions. ${ }^{58}$ As can be seen from Figure S10a,b, crude AIS QDs prepared with a $\mathrm{Ag} / \mathrm{In}$ ratio of $1 / 5$ could be split into eight fractions emitting from the red (640 $\mathrm{nm})$ to the yellow $(550 \mathrm{~nm})$ regions. The highest PL QY $(35.5 \%)$ was measured for the orange- 
emitting QDs (590 nm, sample 4) while yellow-emitting dots exhibit much weaker PL QYs (10.5 and 3.8\% for QDs emitting at $556 \mathrm{~nm}$ and $550 \mathrm{~nm}$, respectively, samples 7 and 8) (Figure S10c). A similar experiment conducted on AIZS QDs $(\mathrm{Ag} / \mathrm{In}=1 / 5)$ shows that the crude QDs solution could be divided into 13 fractions emitting from $620 \mathrm{~nm}$ to $518 \mathrm{~nm}$ (Figure 11a,b). A very high PL QY of $77.8 \%$ was measured for the yellow-emitting (546 nm) sample 8 (Figure 11c). A significant decrease of the FWHM of the PL emission spectra was also observed during the selection (ca. $120 \mathrm{~nm}$ for samples 1-3 and $103 \mathrm{~nm}$ for samples 6-9), suggesting that AIZS QDs with the highest PL QYs were the less heterogeneous in size and composition. As previously observed for AIS QDs, the largest (fractions 1 and 2) and the smallest (fractions 1113) nanocrystals exhibit the lowest PL QY. These results are in good accordance with those obtained for AIS and AIZS QDs after a size selection. ${ }^{31}$ The higher PL QYs measured for medium sized QDs (samples 6-9) compared to the crude mixture obtained after synthesis (PL QY of 65\%) originates from the removal of the smallest and of the largest nanocrystals from these fractions. 

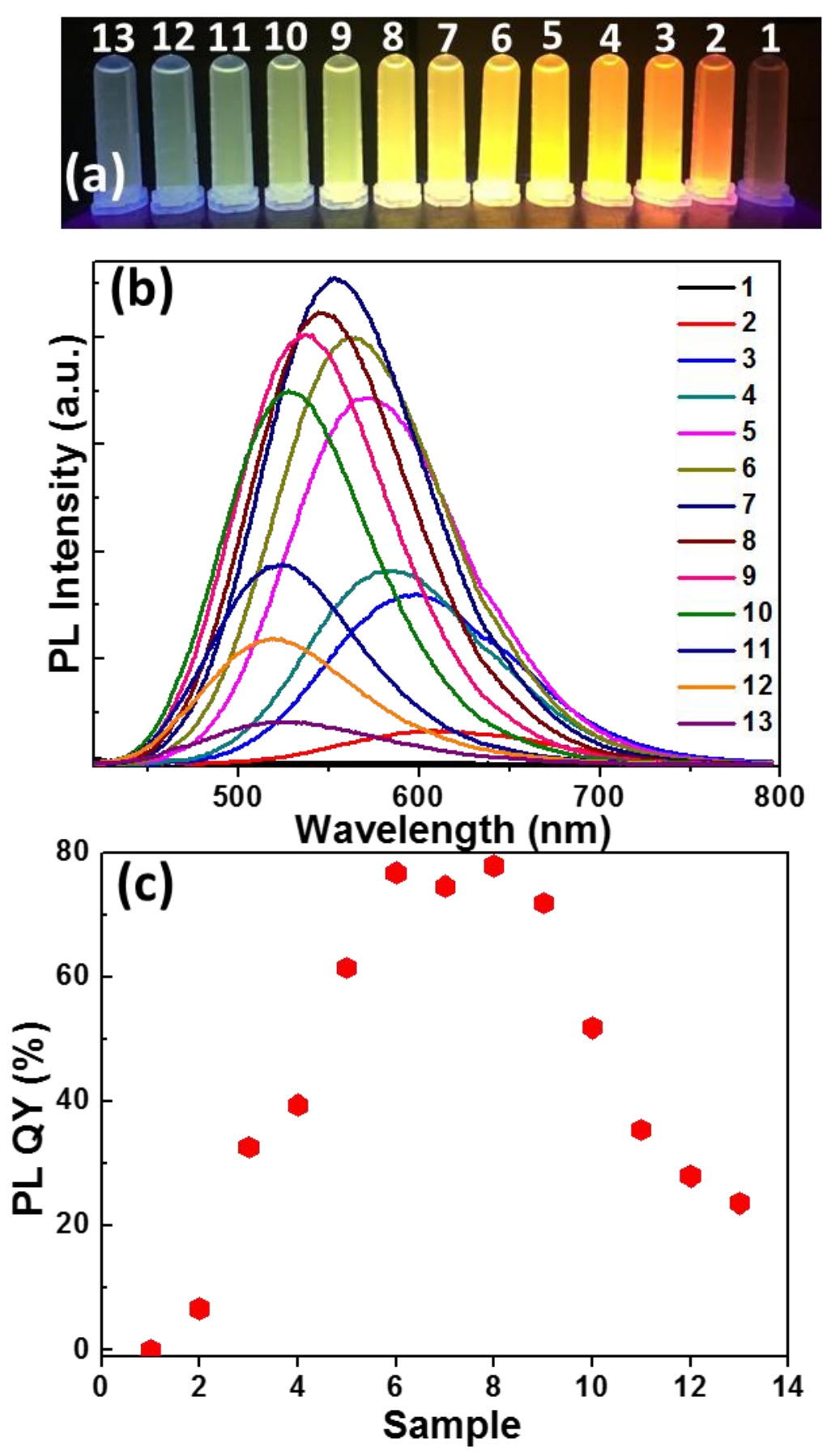

Figure 11. (a) Digital photograph taken under UV-light illumination of size and compositionselected AIZS QDs, (b) PL emission spectra and (c) PL QYs in water of AIZS QDs after size and composition-selective precipitation. 
The PL lifetimes of some of the samples obtained after the post-processing selection were also measured (see Figure 12a,b for the digital photograph of these samples exposed to UV-light illumination and their corresponding PL emission spectra, respectively). As described previously, the PL decay curves of the dots were best fitted using a biexponential function (Figure $12 \mathrm{c}$ and Table 3). Both $\tau_{\mathrm{av}}$ and $\mathrm{A}_{2} / \mathrm{A}_{1}$ ratios are the highest for the samples exhibiting the best PL QYs (71, 77 and 69\% for samples 4, 5 and 6, respectively), indicating that the D-A pair emission mainly contribute to the PL emission process of these AIZS QDs. The weaker $\tau_{\mathrm{av}}$ values determined for the smallest nanocrystals (samples 6 and 7) originates from the higher contribution of the surface trap states due to larger surface-to-volume ratio of these QDs and to the higher probability of recombination via these surface states. The high contribution of surface trap states for the largest QDs (samples 1-3) is more surprising as the probability of D-A pair emission to occur within these particles should be increased. ${ }^{59}$ The very weak PL QY of sample 1 may originate from the weak confinement of the charge carriers because of the large QDs size. 

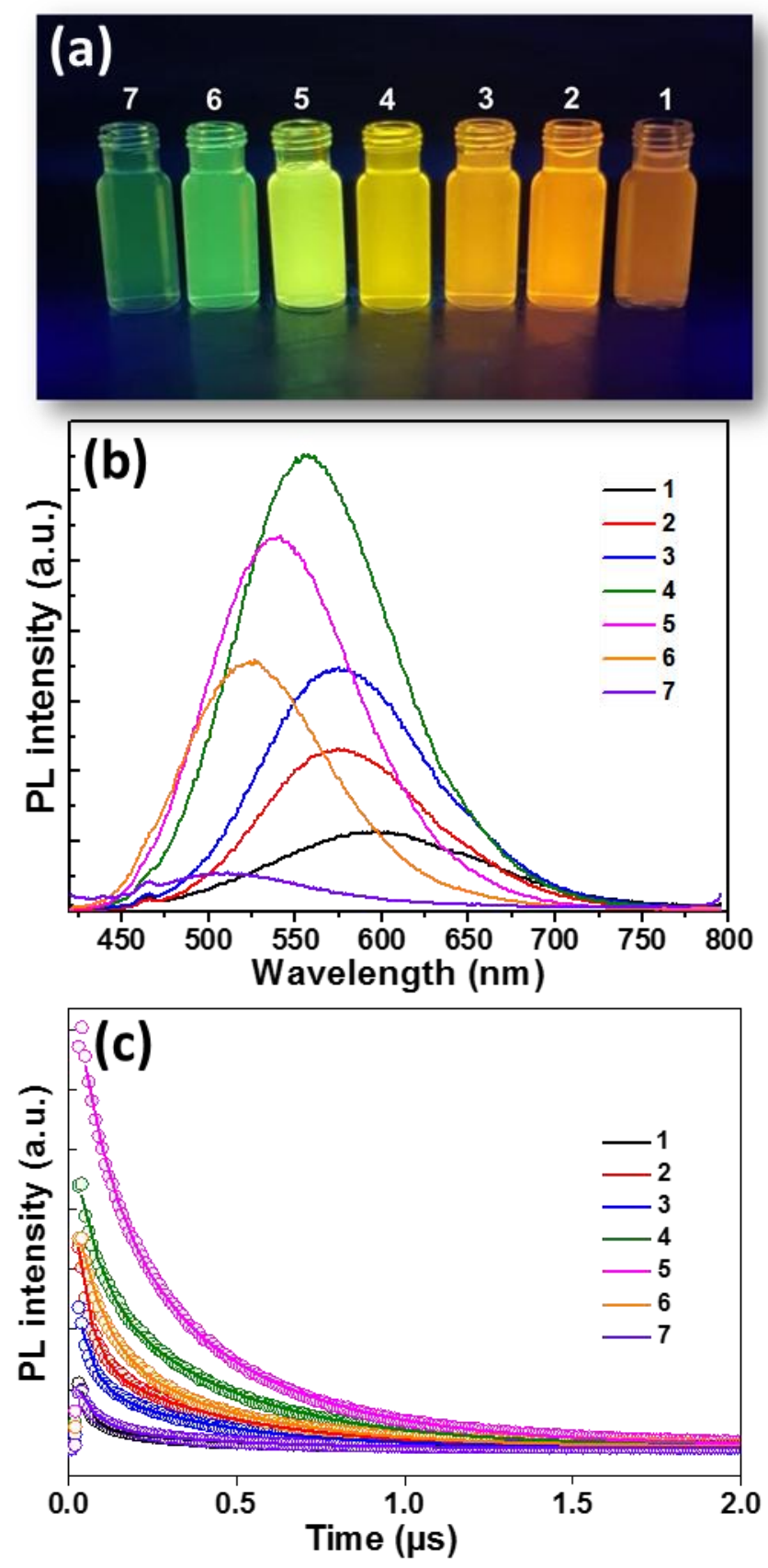

Figure 12. (a) Digital photograph taken under UV-light illumination, (b) PL emission spectra and (c) PL decay curves of AIZS QDs after size and composition-selective precipitation. 
Table 3. Lifetimes and fitting results for samples 1-7 originating from the AIZS QDs sizeselection.

\begin{tabular}{|c|c|c|c|c|c|}
\hline Sample & $\mathrm{A}_{1}$ & $\begin{array}{l}\tau_{1} \\
(\mu \mathrm{s})\end{array}$ & $\mathrm{A}_{2}$ & $\begin{array}{l}\tau_{2} \\
(\mu \mathrm{s})\end{array}$ & $\begin{array}{l}\tau_{\mathrm{av}} \\
(\mu \mathrm{s})\end{array}$ \\
\hline 1 & 0.0104 & 0.00319 & 0.00189 & 0.356 & 0.0574 \\
\hline 2 & 0.0190 & 0.0417 & 0.00797 & 0.406 & 0.149 \\
\hline 3 & 0.0122 & 0.0429 & 0.00572 & 0.400 & 0.157 \\
\hline 4 & 0.0136 & 0.0680 & 0.0146 & 0.416 & 0.248 \\
\hline 5 & 0.0201 & 0.109 & 0.0214 & 0.434 & 0.277 \\
\hline 6 & 0.0136 & 0.0765 & 0.00962 & 0.403 & 0.212 \\
\hline 7 & 0.00495 & 0.0550 & 0.00211 & 0.351 & 0.143 \\
\hline
\end{tabular}

\section{CONCLUSION}

AIS and AIZS QDs with various $\mathrm{Ag} / \mathrm{In}$ ratios varying from $1 / 60$ to $2 / 1$ were efficiently prepared via an aqueous method using 3-MPA as capping ligand. An atypical evolution of the PL emission maximum of AIS cores was observed when increasing the Ag/In ratio. The blue shift 
observed with the increase of the $\mathrm{Ag} / \mathrm{In}$ ratio is linked to $\mathrm{Ag}$ and In precursors formed in the 3MPA solution. The PL QYs of AIS cores is modest (less than 10\%) but those of AIZS QDs is markedly increased (up to $65 \%$ ) due to the alloying of AIS cores with $\mathrm{ZnS}$ followed by $\mathrm{ZnS}$ overcoating. The PL emission of AIZS QDs can be tuned from ca. 540 to $610 \mathrm{~nm}$ by varying the $\mathrm{Ag} / \mathrm{In}$ ratio, the amount of the used $\mathrm{Zn}^{2+}$ precursor or the reaction temperature. AIZS QDs exhibit long PL decay times (ca. $0.3 \mu \mathrm{s}$ ) and excellent colloidal stability and photostability, suggesting that these nanocrystals have a high potential for biological applications. Size and composition-selections on AIS and AIZS QDs were also conducted using the precipitation technique and allowed to split up to 13 fractions of AIZS QDs emitting from the green to the red region and exhibiting PL QY up to $77.8 \%$, which is the highest value reported to date for AIZS QDs prepared in aqueous solution.

\section{EXPERIMENTAL SECTION}

Reagents. Indium nitrate hydrate $\mathrm{In}\left(\mathrm{NO}_{3}\right)_{3} \cdot \mathrm{xH}_{2} \mathrm{O}(99.99 \%$, Sigma), silver nitrate $(>99.5 \%$, Fluka), zinc acetate dihydrate $\mathrm{Zn}(\mathrm{OAc})_{2} \cdot 2 \mathrm{H}_{2} \mathrm{O}$ (>98\%, Sigma), 3-mercaptopropionic acid ( $>99 \%$, Sigma), sodium sulfide nonahydrate $\mathrm{Na}_{2} \mathrm{~S}_{2} 9 \mathrm{H}_{2} \mathrm{O}(98 \%$, Alfa-Aesar), sodium hydroxide $(>99 \%$, VWR) were purchased and used as received without further purification. All solutions were prepared using Milli-Q water (18.2 M $\Omega . c m$, Millipore) as solvent.

Synthesis of $\mathbf{A g I n S}_{2}$ (AIS) QDs. For all syntheses, the precursors amount $\mathrm{n}\left(\mathrm{Ag}^{+}+\mathrm{In}^{3+}\right)$ was fixed at $0.5 \mathrm{mmol}$ and the $\mathrm{Ag} / \mathrm{In}$ ratio varied from $1 / 60$ to $2 / 1$. A representative synthesis of AIS QDs using a $\mathrm{Ag} / \mathrm{In}$ ratio of $1 / 5$ is described. In a three-neck flask, $0.083 \mathrm{mmol}$ of $\mathrm{AgNO}_{3}, 0.417$ mmol of $\mathrm{In}\left(\mathrm{NO}_{3}\right)_{3} .5 \mathrm{H}_{2} \mathrm{O}$ and $25 \mathrm{~mL}$ of a $0.2 \mathrm{M}$ aqueous solution of 3-MPA were loaded and the $\mathrm{pH}$ of the solution was adjusted to 8.5 by adding a $2 \mathrm{M} \mathrm{NaOH}$ aqueous solution. The mixture 
was deareated by bubbling argon for $30 \mathrm{~min}$. Next, $\mathrm{Na}_{2} \mathrm{~S} .9 \mathrm{H}_{2} \mathrm{O}(0.35 \mathrm{mmol})$ in $2 \mathrm{~mL}$ water was quickly injected and the mixture stirred for $15 \mathrm{~min}$ at room temperature. Next, the temperature was raised to $100^{\circ} \mathrm{C}$. During the growth of AIS QDs, aliquots were taken every 30 min to monitor the growth of AIS QDs by UV-visible absorption and PL spectroscopy.

Synthesis of $\left(\mathbf{A g I n S}_{2}\right) \mathbf{x}(\mathbf{Z n S})_{1-\mathbf{x}}(\mathbf{A I Z S})$ QDs. To the crude solution of AIS QDs at $100^{\circ} \mathrm{C}, 1$ mmol of $\mathrm{Zn}(\mathrm{OAc})_{2} \cdot 2 \mathrm{H}_{2} \mathrm{O}$ in $2 \mathrm{~mL}$ water was slowly injected and the mixture maintained at $100^{\circ} \mathrm{C}$ for $90 \mathrm{~min}$. After cooling to room temperature, the mixture was centrifuged (1700 $\mathrm{g}$ for $15 \mathrm{~min}$ ) to remove aggregates. Next, AIZS QDs were precipitated using EtOH, recovered by centrifugation (1700 g for $15 \mathrm{~min}$ ), and washed three times with EtOH before drying under vacuum at room temperature and characterization.

Characterization. Transmission electron microscopy (TEM) images were taken by placing a drop of the particles dispersed in water onto a carbon film-supported copper grid. Samples were studied using a Philips CM200 instrument operating at $200 \mathrm{kV}$. The X-ray powder diffraction (XRD) diagrams were measured using Panalytical X'Pert Pro MPD diffractometer using $\mathrm{Cu} \mathrm{K} \alpha$ radiation. The powder samples were placed on a silicon zero-background sample holder and the XRD patterns were recorded at room temperature using $\mathrm{Cu} \mathrm{K}_{\alpha}$ radiation $(\lambda=0.15418 \mathrm{~nm})$. XRD diffraction patterns were analyzed using TOPAS (Bruker AXS, Version 4-2). Hydrodynamic QDs sizes, polydispersity indexes (PDI), and zeta potential measurements were determined by dynamic light scattering (DLS) on a Zetasizer Nano ZS (Malvern Panalytical, UK), Cuvette DTS1070.

All the optical measurements were conducted at room temperature $\left(20 \pm 1{ }^{\circ} \mathrm{C}\right)$ under ambient conditions. FT-IR spectra were recorded on a Brucker ALPHA spectrometer. Absorption spectra were recorded on a Thermo Scientific Evolution 220 UV-visible spectrophotometer. 
Photoluminescence emission spectra were measured on a Horiba Fluoromax-4 Jobin Yvon spectrofluorimeter. PL spectra were spectrally corrected and relative PL QYs were determined relative to Rhodamine 6G in ethanol (PL QY $=94 \%$ ). The absolute PL QYs of AIZS QDs were measured by using a Horiba Fluorolog spectrometer equipped with a Quanta $\Phi$ integration sphere. These QYs measurements were obtained at an excitation wavelength equal to $400 \mathrm{~nm}$, provided a $450 \mathrm{~W}$ xenon arc lamp source.

For the time resolved photoluminescence (TR-PL) experiments, the QDs were pumped by the $355 \mathrm{~nm}$ line of a frequency-tripled YAG (yttrium aluminium garnet):Nd laser. The laser pulse frequency, energy and duration were typically equal to $10 \mathrm{~Hz}, 50 \mu \mathrm{J}$ and $10 \mathrm{~ns}$, respectively. The PL signal was analyzed by a monochromator equipped with a 600 grooves $/ \mathrm{mm}$ grating and by a photomultiplier tube cooled at $190 \mathrm{~K}$. The rise time of the detector is equal to around $3 \mathrm{~ns}$.

\section{ASSOCIATED CONTENT}

\section{Supporting Information.}

The Supporting Information is available free of charge on the ACS Publications website at DOI: 10.1021/acs.inorgchem.0c00347

Additional details regarding spectroscopic, EDX and XRD characterizations, including Figures S1-S10.

AUTHOR INFORMATION

\section{Corresponding Author}


*E-mail: raphael.schneider@univ-lorraine.fr

\section{Author Contributions}

The manuscript was written through contributions of all authors. All authors have given approval to the final version of the manuscript.

\section{Notes}

The authors declare no competing financial interest.

\section{ACKNOWLEDGMENT}

M. Mrad thanks the University of Carthage for financial support.

\section{REFERENCES}

(1) Torimoto, T.; Kameyama, T.; Kuwabata, S. Photofunctional Materials Fabricated with Chalcopyrite-Type Semiconductor Nanoparticles Composed of $\mathrm{AgInS}_{2}$ and Its Solid Solutions. $J$. Phys. Chem. Lett. 2014, 5, 336-347.

(2) Liu, S.; Su, X. The Synthesis and Application of I-III-VI Type Quantum Dots. RSC Adv. 2014, 4, 43415-43428.

(3) Chen, B.; Pradhan, N.; Zhong, H. From Large-Scale Synthesis to Lighting Device Applications of Ternary I-III-VI Semiconductor Nanocrystals: Inspiring Greener Material Emitters. J. Phys. Chem. Lett. 2018, 9, 435-445.

(4) Regulacio, M.D.; Han, M.-Y. Multinary I- III-VI 2 and $\mathrm{I}_{2}-\mathrm{II}-\mathrm{IV}_{2}-\mathrm{VI}_{4}$ Semiconductor Nanostructures for Photocatalytic Applications. Acc. Chem. Res. 2016, 49, 511-519. 
(5) Yang, W.; Gong, X.; Chang, J. Development of Novel Cadmium-Free AgInS 2 Semiconductor Nanoparticles. J. Nanosci. Nanotechnol. 2016, 16, 2172-2183.

(6) Girma, W.M.; Fahmi, M.Z.; Permadi, A.; Abati, M.A.; Chang, J.-Y. Synthetic Strategies and Biomedical Applications of I-III-VI Ternary Quantum Dots. J. Mater. Chem. B 2017, 5, 6193-6216.

(7) Das, A.; Snee, P.T. Synthetic Developments of Nontoxic Quantum Dots. Chem. Phys. Chem. 2016, 17, 598-617.

(8) Zhong, H; Bai, Z.; Zou, B. Tuning the Luminescence Properties of Colloidal I-III-VI Semiconductor Nanocrystals for Optoelectronics and Biotechnology Applications. J. Phys. Chem. Lett. 2012, 3, 3167-3175.

(9) S.P. Hong, H.K. Park, J.H. Oh, H. Yang, Y.R. Do, Comparisons of the Structural and Optical Properties of o-AgInS 2 , t-AgInS 2 , and c-AgIn ${ }_{5} \mathrm{~S}_{8}$ Nanocrystals and Their Solid-Solution Nanocrystals with ZnS. J. Mater. Chem. 2012, 22, 18939-18949.

(10) Mao, B.; Chuang, C.-H.; Lu, F.; Sang, L.; Zhu, J.; Burda, C. Study of the Partial Ag-toZn Cation Exchange in AgInS ${ }_{2} / \mathrm{ZnS}$ Nanocrystals. J. Phys. Chem. C 2013, 117, 648-659.

(11) Song, J.; Ma, C.; Zhang, W.; Li, X.; Zhang, W.; Wu, R.; Cheng, X.; Ali, A.; Yang, M.; Zhu, L.; Xia, R.; Xu, X. Bandgap and Structure Engineering via Cation Exchange: From Binary $\mathrm{Ag}_{2} \mathrm{~S}$ to Ternary $\mathrm{AgInS}$, Quaternary AgZnInS alloy and AgZnInS/ZnS Core/Shell Fluorescent Nanocrystals for Bioimaging. ACS Appl. Mater. Interfaces 2016, 8, 24826-24836.

(12) Jeong, S.; Yoon, S.; Chun, S.Y.; Yoon, H.C.; Han, N.S.; Oh, J.H.; Park, S.M.; Do, Y.R.; Song, J.K. Enhancement Mechanism of Photoluminescence Quantum Yield in Highly Efficient 
ZnS-AgIn ${ }_{5} \mathrm{~S}_{8}$ Quantum Dots with Core/Shell Structures. J. Phys. Chem. C 2018, 122, 1012510132.

(13) You, S.H.; Hong, K.J.; Youn, C.J.; Jeong, T.S.; Moon, J.D.; Kim, H.S.; Park, J.S. Origin of Point Defects in $\mathrm{AgInS}_{2} / \mathrm{GaAs}$ Epilayer Obtained from Photoluminescence Measurement. $J$. Appl. Phys. 2001, 90, 3894-3898.

(14) Hamanaka, H.; Ogawa, T.; Tsuzuki, M. Photoluminescence Properties and Its Origin of $\mathrm{AgInS}_{2}$ Quantum Dots with Chalcopyrite Structure. J. Phys. Chem. C 2011, 115, 1786-1792.

(15) Stroyuk, O.; Weigert, F.; Raevskaya, A.; Spranger, F.; Würth, C.; Resch-Ganger, U.; Gaponik, N.; Zahn, D.R.T. Inherently Broadband Photoluminescence in Ag-In-S/ZnS Quantum Dots Observed in Ensemble and Single-Particle Studies. J. Phys. Chem. C 2019, 123, 2632-2641.

(16) Chung, W.; Jung, H.; Lee, C.H.; Kim, S.H. Extremely High Color Rendering White Light from Surface Passivated Carbon Dots and Zn-doped $\operatorname{AgInS}_{2}$ Nanocrystals. J. Mater. Chem. C 2014, 2, 4227-4232.

(17) Chevallier, T.; Le Blevennec, G.; Chandezon, F. Photoluminescence Properties of $\mathrm{AgInS}_{2}-\mathrm{ZnS}$ Nanocrystals : the Critical Role of Surface. Nanoscale 2016, 8, 7612-7620.

(18) Kameyama, T.; Takahashi, T.; Machida, T.; Kamiya, Y.; Yamamoto, T.; Kuwabata, S.; Torimoto, T. Controlling the Electronic Energy Structure of $\mathrm{ZnS}-\mathrm{AgInS}_{2}$ Solid Solution Nanocrystals for Photoluminescence and Photocatalytic Hydrogen Evolution. J. Phys. Chem. C 2015, 119, 24740-24749. 
(19) Galiyeva, P.; Alem, H.; Rinnert, H.; Balan, L.; Blanchard, S.; Medjahdi, G.; Uralbekov, B.; Schneider, R. Highly Fluorescent, Color Tunable and Magnetic Quaternary Ag-In-Mn-Zn-S Quantum Dots. Inorg. Chem. Front. 2019, 6, 1422-1431.

(20) Choi, D.B.; Kim, S.; Yoon, H.C.; Ko, M.; Yang, H.; Do, Y.R. Color-Tunable Ag-In-Zn-S Quantum-Dot Light-Emitting Devices Realizing Green, Yellow and Amber Emissions. J. Mater. Chem. C 2017, 5, 953-959.

(21) Bujak, P.; Wrobel, Z.; Penkala, M.; Koturica, K.; Kmita, A.; Gajewska, M.; Ostrowski, A.; Kowalik, P.; Pron, A. Highly Luminescent Ag-In-Zn-S Quaternary Nanocrystals: Growth Mechanism and Surface Chemistry Elucidation. Inorg. Chem. 2019, 58, 1358-1370.

(22) Deng, D.; Cao, J.; Qu, L.; Achilefu, S.; Gu, Y. Highly Luminescent Water-Soluble Quaternary Zn-Ag-In-S Quantum Dots for Tumor Cell-Targeted Imaging. Phys. Chem. Chem. Phys. 2013, 15, 5078-5083.

(23) Xiong, W.-W.; Yang, G.-H.; Wu, X.-C.; Zhu, J.-J. Microwave-Assisted Synthesis of Highly Luminescent $\mathrm{AgInS}_{2} / \mathrm{ZnS}$ Nanocrystals for Dynamic Intracellular $\mathrm{Cu}(\mathrm{II})$ Detection. J. Mater. Chem. B 2013, 1, 4160-4165.

(24) Deng, D.; Qu, L.; Cheng, Z.; Achilefu, S.; Gu, Y. Highly Luminescent Water-Soluble Quaternary Zn-Ag-In-S Quantum Dots and Their Unique Precursor S/In Ratio-Dependent Spectral Shifts. J. Lumin. 2014, 146, 364-370.

(25) Zhao, P.; Zhang, J.; Zhu, Y.; Yang, X.; Jiang, X.; Yuan, Y.; Liu, C.; Li, C. A Novel Strategy for the Aqueous Synthesis of Down-/Up-Conversion Nanocomposites for Dual-Modal Cell Imaging and Drug Delivery. J. Mater. Chem. B 2014, 2, 8372-8377. 
(26) Mir, I.A.; Radhakrishanan, V.S.; Rawat, K.; Prasad, T.; Bohidar, H.B. Bandgap Tunable AgInS Based Quantum Dots for High Contrast Cell Imaging with Enhanced Photodynamic and Antifungal Applications. Sci. Rep. 2018, 8, 9322.

(27) Stroyuk, O.; Raevskaya, A.; Spranger, F.; Selyshchev, O.; Dzhagan, V.; Schulze, S.; Zahn, D.R.T.; Eychmüller, A. Origin and Dynamics of Highly-Efficient Broadband Photoluminescence of Aqueous Glutathione-Capped Size-Selected Ag-In-S Quantum Dots. $J$. Phys. Chem. C 2018, 122, 13648-13658.

(28) Chen, T.; Hu, X.; Xu, Y.; Wang, L.; Jiang, W.; Jiang, W.; Xie, Z. Hydrothermal Synthesis of Highly Fluorescent Ag-In-S/ZnS Core/Shell Quantum Dots for White LightEmitting Diodes. J. Alloy. Compd. 2019, 804, 119-127.

(29) Hu, X.; Chen, T.; Xu, Y.; Wang, M.; Jiang, W.; Jiang, W. Hydrothermal Synthesis of Bright and Stable AgInS ${ }_{2}$ Quantum Dots with Tunable Visible Emission. J. Lumin. 2018, 200, 189-195.

(30) Regulacio, M.D.; Win, K.Y.; Lo, S.L.; Zhang, S.-Y.; Zhang, X.; Wang, S.; Han, M.-Y.; Zheng, Y. Aqueous Synthesis of Highly Luminescent $\mathrm{AgInS}_{2}-\mathrm{ZnS}$ Quantum Dots and their Biological Applications. Nanoscale 2013, 5, 2322-2327.

(31) Raevskaya, A.; Lesnyak, V.; Haubold, D.; Dzhagan, V.; Stroyuk, O.; Gaponik, N.; Zahn, D.R.T.; Eychmüller, A. A Fine Size Selection of Brightly Luminescent Water-Soluble Ag-In- S and Ag-In-S/ZnS Quantum Dots. J. Phys. Chem. C 2017, 121, 9032-9042. 
(32) Y. Liu, X. Tang, M. Deng, T. Zhu, Y. Bai, D. Qu, X. Huang, F. Qiu, One-Step Aqueous Synthesis of Highly Luminescent Hydrophilic AgInZnS Quantum Dots. J. Lumin. 2018, 202, 71 76.

(33) Chen, Y.; Wang, Q.; Zha, T.; Min, J.; Gao, J.; Zhou, C.; Li, J.; Zhao, M.; Li, S. Green and Facile Synthesis of High-Quality Water-Soluble Ag-In-S/ZnS Core/Shell Quantum Dots with Obvious Bandgap and Sub-Bandgap Excitations. J. Alloy. Compd. 2018, 753, 364-370.

(34) Song, J.; Jiang, T.; Guo, T.; Liu, L.; Wang, H.; Xia, T.; Zhang, W.; Ye, X.; Yang, M.; Zhu, L.; Xia, R.; Xu, X. Facile Synthesis of Water-Soluble Zn-Doped AgIn ${ }_{5} \mathrm{~S}_{8} / \mathrm{ZnS}$ Core/Shell Fluorescent Nanocrystals and Their Biological Application. Inorg. Chem. 2015, 54, 1627-1633.

(35) Wei, C.; Wei, X.; Hu, Z.; Yang, D.; Mei, S.; Zhang, G.; Su, D.; Zhang, W.; Guo, R. A Fluorescent Probe for $\mathrm{Cd}^{2+}$ Detection Based on Aggregation Induced Emission Enhancement of Aqueous Zn-Ag-In-S Quantum Dots. Anal. Methods 2019, 11, 2559-2564.

(36) Soheyli, E.; Azad, D.; R. Sahraei, Hatamnia, A.A.; Rostamzad, A.; Alinazari, M. Synthesis and Optimization of Emission Characteristics of Water-Dispersible Ag-In-S Quantum Dots and Their Bactericidal Activity. Colloids Surf. B: Biointerfaces 2019, 182, 110389.

(37) Yang, W.; Guo, W.; Zhang, T.; Yang, W.; Su, L.; Fang, L.; Wang, H.; Gong, X.; Chang, J. Synthesis of Aqueous AgInS/ZnS@PEI as Self-Indicating Nonviral Vector for Plasmid DNA Self-Tracking Delivery. J. Mater. Chem. B 2015, 3, 8518-8527.

(38) Wang, L.; Kang, X.; Pan, D. Gram-Scale Synthesis of Hydrophilic PEI-Coated AgInS 2 Quantum Dots and Its Application in Hydrogen Peroxide/Glucose Detection and Cell Imaging. Inorg. Chem. 2017, 56, 6122-6130. 
(39) Kang, X.; Huang, L.; Yang, Y.; Pan, D. Scaling up the Aqueous Synthesis of Visible Light Emitting Multinary $\mathrm{AgInS}_{2} / \mathrm{ZnS}$ Core/Shell Quantum Dots. J. Phys. Chem. C 2015, 119, 7933-7940.

(40) Carvalho, I.C.; Mansur, A.A.P.; Carvalho, S.M.; Florentino, R.M.; Mansur, H.S. Lcysteine and Poly-L-arginine Grafted Carboxymethyl Cellulose/Ag-In-S Quantum Dot Fluorescent Nanohybrids for in Vitro Bioimaging of Brain Cancer Cells. Int. J. Biol. Macromol. 2019, 133, 739-753.

(41) Santana, C.P.; Mansur, A.A.P.; Carvalho, S.M.; da Silva-Cunha Jr, A.; Mansur, H.S. BiFunctional Quantum Dot-Polysaccharide-Antibody Immunoconjugates for Bioimaging and Killing Brain Cancer Cells in Vitro. Mater. Lett. 2019, 252, 333-337.

(42) Song, J. ; Ma, C. ; Zhang, W.; Li, X. ; Zhang, W.; Wu, R.; Cheng, X.; Ali, A.; Yang, M.; Zhu, L.; Xia, R.; Xu, X. Bandgap and Structure Engineering via Cation Exchange : From Binary $\mathrm{Ag}_{2} \mathrm{~S}$ to Ternary $\mathrm{AgInS}_{2}$, Quaternary AgZnInS alloy and AgZnInS/ZnS Core/Shell Fluorescent Nanocrystals for Bioimaging. ACS Appl. Mater. Interfaces 2016, 8, 24826-24836.

(43) Zhang, J.; Li, J.; Zhang, J.; Xie, R.; Yang, W. Aqueous Synthesis of ZnSe Nanocrystals by Using Glutathione as Ligand: The $\mathrm{pH}-$ Mediated Coordination of $\mathrm{Zn}^{2+}$ with Glutathione. J. Phys. Chem. C 2010, 114, 11087-11091.

(44) Zhang, H.; Wang, D.; H. Mohwäld, H. Ligand-selective Aqueous Synthesis of One Dimensional CdTe Nanostructures, Angew. Chem. Int. Ed. 2006, 45, 748-751.

(45) Baker, D.R.; Kamat, P.V. Tuning the Emission of CdSe Quantum Dots by Controlled Trap Enhancement. Langmuir 2010, 26, 11272-11276. 
(46) Takahashi, T.; Kudo, A.; Kuwabata, S.; Ishikawa, A.; Ishihara, H.; Tsuboi, Y.; Torimoto, T. Plasmon-Enhanced Photoluminescence and Photocatalytic Activities of Visible-LightResponsive ZnS-AgInS 2 Solid Solution Nanoparticles. J. Phys. Chem. C 2013, 117, 2511-2520.

(47) Tsuji, L.; Kato, H.; Kobayashi, H.; Kudo, A. Photocatalytic $\mathrm{H}_{2}$ Evolution Reaction from Aqueous Solutions over Band Structure-Controlled (AgIn) $\mathrm{Zn}_{2(1-\mathrm{x})} \mathrm{S}_{2}$ Solid Solution Photocatalysts with Visible-Light Response and Their Surface Nanostructures. J. Am. Chem. Soc. 2004, 126, 13406-13413.

(48) Kojima, N.; Sugiura, Y.; Tanaka, H. Polynuclear and Mononuclear Complex Formation between Indium (III) and Sulfhydryl-Containing Bidentate Ligands. Chem. Pharm. Bull. 1978, 26, 579-584.

(49) Tombeux, J.J.; Schaubroeck, J.; Huys, C.T.; de Brabander, H.F.; Goeminne, A.M. A Potentiometric Study of the AgI Complexes of Some Sulphur Containing Amino Acids. $Z$. Anorg. Allg. Chem. 1984, 517, 235-240.

(50) Li, L.; Pandey, A.; Werder, D.J.; Khanal, B.P.; Pietryga, J.M.; Klimov, V.I. Efficient Synthesis of Highly Luminescent Copper Indium Sulfide-Based Core/Shell Nanocrystals with Surprisingly Long-Lived Emission. J. Am. Chem. Soc. 2011, 133, 1176-1179.

(51) Würth, C.; Grabolle, M.; Pauli, J.; Spieles, M.; Resch-Genger, U. Relative and Absolute Determination of Fluorescence Quantum Yields of Transparent Samples. Nat. Protoc. 2013, 8, $1535-1550$. 
(52) Song, J.; Ma, C.; Zhang, W.; Yang, S.; Wang, S.; Lv, L.; Zhu, L.; Xia R.; Xu, X. Tumor Cell-Targeted $\mathrm{Zn}_{3} \mathrm{In}_{2} \mathrm{~S}_{6}$ and $\mathrm{Ag}-\mathrm{Zn}-\mathrm{In}-\mathrm{S}$ Quantum Dots for Color Adjustable Luminophores. $J$. Mater. Chem. B 2016, 4, 7909-7918.

(53) Dai, M.; Ogawa, S.; Kameyama, T.; Okazaki, K.-I.; Kudo, A.; Kuwabata, S.; Tsuboi Y.; Torimoto, T. Tunable Photoluminescence from the Visible to Near-Infrared Wavelength Region of Non-Stoichiometric AgInS 2 Nanoparticles. J. Mater. Chem. 2012, 22, 12851-12858.

(54) Mao, B.; Chuang, C.-H.; McCleese, C.; Zhu, J.; Burda, C. Near-Infrared Emitting $\mathrm{AgInS}_{2} / \mathrm{ZnS}$ Nanocrystals. J. Phys. Chem. C 2014, 118, 13883-13889.

(55) Liu, Z.Y.; Tang, A.W.; Wang, M.; Yang, C.H.; Teng, F. Heating-up Synthesis of Cadimum-Free and Color-Tunable Quaternary and Five-Component Cu-In-Zn-S-based Semiconductor Nanocrystals. J. Mater. Chem. C 2015, 3, 10114-10120.

(56) Zeng, B.; Chen, F.; Liu, Z.; Guan, Z.; Li, X.; Teng, F.; Tang, A. Seeded-Mediated Growth of Ternary Ag-In-S and Quaternary Ag-In-Zn-S Nanocrystals from Binary $\mathrm{Ag}_{2} \mathrm{~S}$ Seeds and the Composition-Tunable Optical Properties. J. Mater. Chem. C 2019, 7, 1307-1315.

(57) Raevskaya, A.; Rozovik, O.; Novikova, A.; Selyshchev, O.; Stroyuk, O.; Dzhagan, V.; Goryacheva, I.; Gaponik, N.; Zahn, D.R.T.; Eychmüller, A. Luminescence and Photoelectrochemical Properties of Size-Selected Aqueous Copper-Doped Ag-In-S Quantum Dots. $R S C A d v$. 2018, 8, 7550-7557.

(58) Zhuo,S.; Shao, M.; Lee, S.T. Upconversion and Downconversion Fluorescent Graphene Quantum Dots: Ultrasonic Preparation and Photocatalysis, ACS Nano 2012, 6, 1059-1064. 
(59) Akdas, T.; Walker, J.; Segets, D.; Distaso, M.; Winter, B.; Birajdar, B.; Spiecker, E.;

Peukert, W. Investigation of the Size-Property Relationship in $\mathrm{CuInS}_{2}$ Quantum Dots. Nanoscale 2015, 7, 18105-18118.

Table of Contents.

Highly fluorescent and photostable Ag-In-Zn-S (AIZS) QDs were synthesized in aqueous phase using 3-mercaptopropionic acid as capping ligand.
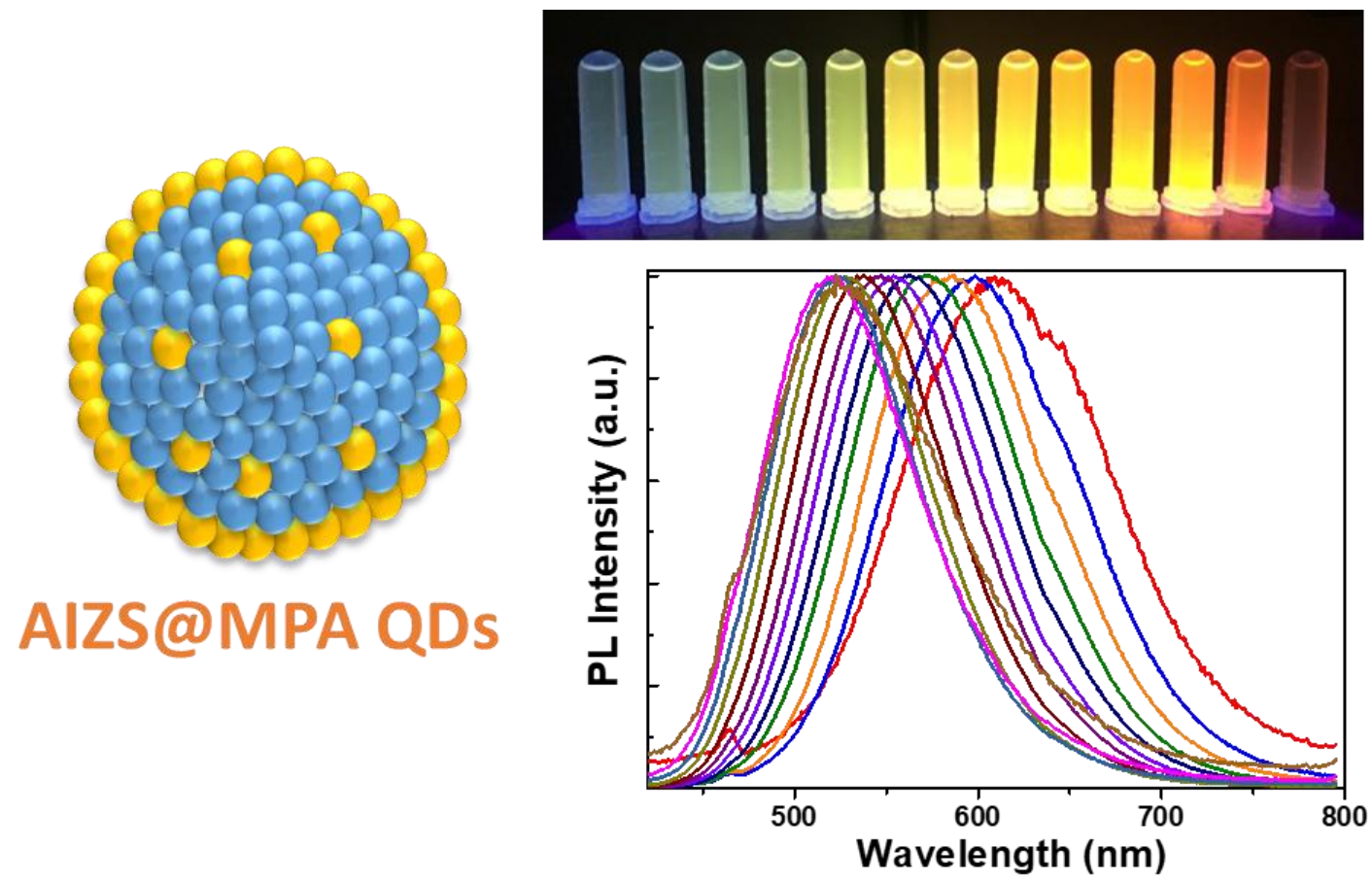